\title{
Alimentação, crescimento e concentração de hemoglobina em crianças menores de um ano, nascidas com baixo peso, atendidas em serviços públicos de saúde.
}

Flávia Alessandra Módolo

Dissertação apresentada ao Programa de PósGraduação em Saúde Pública da Faculdade de Saúde Pública da Universidade de São Paulo para obtenção do título de Mestre em Saúde Pública.

Área de Concentração: Nutrição

Orientadora: Prof Dra. Sophia Cornbluth Szarfarc

São Paulo 
$45645 / 2005$ doc

Autorizo, exclusivamente para fins acadêmicos e científicos, a reprodução total ou parcial desta dissertação, por processos fotocopiadores.

Assinatura: flória módolo

Data: $15 / 02 / 2005$ 
AGRADECIMENTOS

A Profa Dra. SOPHIA CORNBLUTH SZARFARC, pela sua dedicação, paciência, tranqüitidade e competência, fundamentais para a reatização deste trabalho, e pelo empréstimo dos dados da pesquisa.

A Profa Dra. SONNIA BUONGERMINO DE SOUZA, pelo incentivo para a reatização deste trabalho através do empréstimo dos dados da pesquisa.

A GIANA ZARBATO LONGO pela organização do banco de dados.

Ao Conselho Nacional de Desenvolvimento Cientifico e Tecnotógico (CNPq) pela concessão da bolsa de estudos.

A Fundação de Amparo à Pesquisa do Estado de São Pauto (FAPESP) pelo financiamento do projeto maior "Aleitamento materno, dieta de desmame e anemia no primeiro ano de vida, em crianças atendidas na rede pública de saide no Brasil", do qual este trabalhoé parte.

Aos meus pais, pela amizade, paciencia, apoío e incentivo recebidos em todos or momentos da reatização deste trabatho. A minha irmä, peta preocupação e carinho. 
"Quando, seu moço, nasceu meu rebento não era o momento dele rebentar já foi nascendo com cara de fome e eu não tinha nem nome para lhe dar"

Chico Buarque 


\section{RESUMO}

Alimentação, crescimento e concentração de hemoglobina em crianças menores de um ano, nascidas com baixo peso, atendidas em serviços públicos de saúde.

Objetivo: Considerando o significado do peso ao nascer para a evolução da criança, realizou-se estudo com o objetivo de se conhecer a alimentação, estado nutricional, crescimento e concentração de hemoglobina, em crianças nascidas com baixo peso. Metodologia: estudo transversal com crianças em acompanhamento pediátrico de rotina. A prática alimentar foi obtida pelo método status quo, os dados de peso e comprimento foram obtidos das medidas feitas rotineiramente nos serviços de saúde, e a dosagem de hemoglobina foi feita em sangue capilar e utilizou-se o fotômetro portátil HemoCue para leitura. Resultados: Observou-se maior proporção de mães com baixa escolaridade e nos extremos da idade reprodutiva entre as crianças de baixo peso ao nascer. A desnutrição crônica atingiu 30,6\% da amostra, e a anemia, $73,7 \%$. Os valores de hemoglobina foram maiores nas crianças que consomem leite de peito como único alimento lácteo. Verificou-se com freqüência o consumo de água/chá e de leite não materno, mesmo nos primeiros meses de vida, tornando o desmame uma prática precoce. Conclusão: Identificaram-se maiores riscos de desnutrição e anemia na criança nascida com baixo peso. Verificou-se pouca adesão ao aleitamento materno exclusivo e ao predominante. A velocidade de crescimento mostrou forte tendência à recuperação nutricional deste grupo.

Descritores: baixo peso ao nascer, alimentação, estado nutricional, crescimento, concentração de hemoglobina. 


\section{SUMMARY}

Food practice, growth and hemoglobin concentration among children younger than one year old with low birthweight, examined at basic public health care centers in Brazil.

Objective: Considering the significancy of birth weight to infant's development, it was conducted a study to identify the food practice, nutritional status, growth and hemoglobin concentration, among children with low birthweight. Methods: Cross sectional study with infants in routine pediatric examinations. Food practice was obtained by the status quo process; weight and height data were obtained from follow-up files and hemoglobin dosage was assessed by capillary blood, using a portable hemoglobinometer (HemoCue). Results: it was verified higher proportion of mothers with low instruction level among children with low birthweight. Higher proportion of adolescent and mature mothers were also found among these children. Stunting attacked $30,6 \%$ and anaemia, $73,7 \%$. Hemoglobin averages were higher among infants who were breastfed and did not consumpt artificial milk. The consumption of water/tea and cow milk was frequent since the first months of life. Conclusion: It was observed higher risks of undernutrition and anaemia among low birthweight children. It was verified little adhesion to exclusive and partial breastfeeding. Growth increment has showed strong tendency to a nutritional recuperation in this group.

Key words: low birthweight, food practice, nutritional status, growth, hemoglobin concentration. 


\section{ÍNDICE}

Página

1-INTRODUÇÃo 1

2-OBJETIVOS 13

2.1-Geral 13

2.2-Específicos 13

3-METODOLOGIA 14

3.1. Amostra e local de estudo 14

3.2. Aspectos éticos 15

3.3 - Coleta de dados 15

3.3.1. Inquérito Alimentar 16

3.3.2. Inquérito Antropométrico 16

3.3.3. Dosagem de Hemoglobina 17

3.4. Variáveis de estudo 17

3.4.1. Variáveis maternas $\quad 17$

3.4.2. Variáveis da criança 17

3.5. Categorização das variáveis 18

3.6. Análise Estatística 22

4 - RESULTADOS E DISCUSSÃO 23

4.1. Caracterização da amostra 23

4.2. Prática alimentar 30

4.3. Estado nutricional e velocidade de crescimento 39

4.4. Concentração de hemoglobina 43

5 - CONCLUSÕES

6 - CONSIDERAÇÕES FINAIS

7 - REFERÊNCIAS

\section{ANEXOS}

ANEXO 1: Termo de consentimento para participação na pesquisa ANEXO 2: Formulário de registro de dados 


\section{ÍNDICE DE TABELAS}

Página

Tabela 1 - Distribuição das crianças BPN em relação ao número total de crianças, segundo idade (meses).

Tabela 2 - Distribuição das crianças BPN em relação ao número total de crianças, segundo as cidades do estudo.

Tabela 3 - Distribuição porcentual das crianças segundo categoria de aleitamento e 33 idade (meses).

Tabela 4 - Distribuição porcentual das crianças em aleitamento materno (AM) segundo alimentação complementar e idade (meses).

Tabela 5 - Distribuição porcentual das crianças sem aleitamento materno (SAM) 35 segundo tipo de alimento consumido e idade (meses).

Tabela 6 - Distribuição porcentual das crianças segundo composição da alimentação salgada e idade (meses).

Tabela 7- Distribuição porcentual das crianças segundo composição da alimentação salgada e tipo de leite ingerido.

Tabela 8 - Concentração média de hemoglobina ( $g / d L)$ segundo consumo de alimentos fontes de ferro na papa de sal e idade (meses).

Tabela 9 - Concentração média de hemoglobina $(\mathrm{g} / \mathrm{dL})$ segundo tipo de leite ingerido 48 e idade (meses). 


\section{ÍNDICE DE FIGURAS}

Página

Figura 1 - Distribuição do número de crianças segundo peso ao nascer.

Figura 2 - Distribuição da porcentagem de crianças de baixo peso ao nascer e não baixo peso ao nascer segundo a idade materna.

Figura 3 - Distribuição da porcentagem de crianças de baixo peso ao nascer e não baixo peso ao nascer segundo a escolaridade materna.

Figura 4 - Distribuição em porcentagem das crianças de baixo peso ao nascer segundo tipo de leite ingerido e idade (meses).

Figura 5 - Distribuição em porcentagem das crianças de baixo peso ao nascer segundo velocidade de crescimento e idade (meses).

Figura 6 - Concentração média de hemoglobina (média \pm dp) das crianças de baixo peso ao nascer por idade (meses). 


\section{INTRODUÇÃO}

É sobejamente reconhecida a grande influência que o peso de nascimento exerce sobre o estado de saúde e sobrevivência da criança nos primeiros anos de vida. A afirmação da Organização Mundial da Saúde (WHO 1980), de que o peso ao nascer é o fator isolado mais importante na determinação da sobrevida infantil, continua a ser aceita.

No Brasil, a incidência de baixo peso ao nascer (BPN) difere entre as regiões, variando de $12 \%$ no Norte e Nordeste a $10 \%$ no Sul e Sudeste. Por sua contribuição com a morbidade e mortalidade infantil, em especial a perinatal, e pela frequêencia com que ocorre, o BPN, no Brasil, constitui-se em um problema de saúde pública da maior relevância (HORTA e col. 1996a, LIMA e col. 1998).

É definido como nascido com baixo peso o recém-nascido com peso menor que $2500 \mathrm{~g}$ (OMS 1993); muito baixo peso os recém-nascidos com menos de $1500 \mathrm{~g}$ e, como grupo de extremo baixo peso, aqueles com menos de $1000 \mathrm{~g}$ ao nascimento.

Segundo POJDA \& KELLEY (2000), crianças que pesam $2000-2499 \mathrm{~g}$ ao nascimento são 4 vezes mais propensas a morrer durante os primeiros 28 dias de vida do que crianças que pesam $2500-2999 \mathrm{~g}$, e 10 vezes mais propensas a morrer do que crianças que pesam $3000-3499 \mathrm{~g}$. Além disso, os recém-nascidos de baixo peso têm um risco de desenvolver diarréia aguda e de ser hospitalizados por episódios diarréicos de duas a quatro vezes maior, além de apresentarem um risco de contrair pneumonia e 
infecções respiratórias duas vezes maior, e três vezes maior se seu peso for inferior a $2000 \mathrm{~g}$.

Os mesmos autores também verificaram que, no Brasil, $67 \%$ dos óbitos na primeira semana de vida se concentram em crianças nascidas com baixo peso e $47 \%$ dos óbitos no primeiro ano de vida são de crianças BPN.

O conhecimento da importância do baixo peso ao nascer na sobrevida das crianças brasileiras é antigo. Já em 1973, PUFFER \& SERRANO constataram que 73\% das mortes neonatais ocorriam entre crianças nascidas com baixo peso.

Em pesquisa realizada em Pelotas, VICTORA e col. (1989) confirmaram, mais uma vez, o maior risco dos recém-nascidos de BPN. Eles verificaram que as crianças de baixo peso ao nascer apresentaram um risco de morte neonatal (óbitos ocorridos nos primeiros 27 dias de vida) 23,9 vezes maior do que as nascidas com peso adequado, enquanto que para a morte pós-neonatal (óbitos ocorridos dos 28 aos 364 dias de vida) o risco foi de 4,3 vezes.

O baixo peso ao nascer é decorrência de dois processos básicos, que podem ocorrer isoladamente ou em associação: a prematuridade, isto é, o nascimento antes de 37 semanas de gestação, e o retardo de crescimento intra-uterino (RCIU). Nos países desenvolvidos, o baixo peso ao nascer ocorre principalmente devido à prematuridade, enquanto que nos paises em desenvolvimento, a maior parte dos nascimentos de baixo peso é decorrente do RCIU (HORTA e col. 1996a, MONTEIRO e col. 2000a).

Quer a prematuridade quer o RCIU são determinados por diversos fatores, tais como os fatores biológicos, entre os quais desnutrição materna, gravidez múltipla, 
gestação na adolescência (abaixo de 20 anos) ou em idade avançada (a partir de 35 anos), história reprodutiva (aborto prévio, natimorto, morte neonatal ou RBPN prévio), intervalo interpartal curto, baixa comprimento materna (devido em grande parte à própria desnutrição da mãe em sua infância); fatores sociais como fumo durante a gravidez, baixa escolaridade materna e baixa renda familiar, e também devido à atenção pré-natal inadequada (VICTORA e col. 1989, POJDA \& KELLEY 2000; MONTEIRO e col. 2000a; FRANCESCHINI e col. 2003).

O baixo peso ao nascer predispõe a criança a diversas doenças, como desnutrição, anemia, infecções respiratórias e intestinais, além de atraso no desenvolvimento fisico e mental (LEITE 1990). Neste grupo há também dificuldades para a implementação do aleitamento materno (XAVIER e col. 1991). E existem ainda evidências de que individuos nascidos com baixo peso apresentam um risco aumentado de desenvolver doenças crônicas como hipertensão arterial, diabetes mellitus não insulino-dependente, doença cardíaca coronariana e colesterol elevado na idade adulta (POJDA \& KELLEY 2000).

Justifica-se, desta forma, a necessidade de uma atenção especial à criança nascida com baixo peso, com o objetivo de recuperá-la, colocando-a em condição de igualdade com as crianças nascidas com peso adequado.

A alimentação é o primeiro fator relevante para modificar a situação de risco da criança nascida com baixo peso. 
No primeiro ano de vida, a alimentação desempenha um papel decisivo para a saúde da criança, sendo de grande importância a adoção de práticas alimentares adequadas durante este período, especialmente para a criança de baixo peso ao nascer.

A Organização Mundial da Saúde (WHO 2001) recomenda a prática da amamentação exclusiva nos primeiros seis meses de vida, e a manutenção do aleitamento materno, acrescido de alimentos complementares, até os dois anos de vida ou mais.

Cabe salientar que, antes dos seis meses, é geralmente desnecessária a introdução de outros alimentos à criança amamentada ao seio, podendo submetê-la a certos riscos, como torná-la mais vulnerável a diarréias, infecções respiratórias, desnutrição, alergias e obesidade, além de levar à redução da freqüência e intensidade de sucção, reduzindo a produção de leite materno e portanto interferindo na manutenção do aleitamento (WHO/UNICEF 1989; HORTA e col. 1996b; VICTORA e col. 1987).

Estudo conduzido por Victora e col. (1987) constatou que crianças que não recebem leite materno têm 14,2 vezes o risco de óbito por diarréia em comparação às crianças que são amamentadas exclusivamente. Verificou também que crianças em aleitamento misto (que ingerem leite materno e não materno) têm 4,2 vezes o risco de óbito por diarréia em relação às exclusivamente amamentadas.

Neste mesmo estudo, foi verificado que a amamentação também esteve associada com a redução do risco de óbito por infecções respiratórias, sendo que as crianças alimentadas com leite materno e suplemento lácteo apresentaram risco de óbito por infecção respiratória $1,6 \mathrm{vez}$ o risco daquelas exclusivamente amamentadas, e as 
crianças alimentadas somente com suplemento lácteo tiveram um risco 3,6 vezes o risco das crianças em aleitamento exclusivo (VICTORA e col. 1987).

São muitas e importantes as vantagens conhecidas do aleitamento materno, não deixando dúvidas quanto à sua superioridade em relação a outros tipos de leite para crianças pequenas (GIUGLIANI \& VICTORA 1997). O leite humano é o alimento ideal para o crescimento e desenvolvimento do lactente (WHO/UNICEF 1989), além de conter agentes imunológicos que protegem 0 bebê contra infecções, de possuir propriedades antialérgicas, ter boa digestibilidade e ser fornecido bacteriologicamente puro.

A maior parte dos estudos que relacionam a saúde da criança ao aleitamento materno demonstra que as crianças amamentadas tem um melhor estado de saúde do que as que são alimentadas com outros tipos de leite, ao menos nos primeiros meses de vida (OMS/UNICEF 1979).

O aleitamento materno, como já referido, é especialmente importante para os recém-nascidos de baixo peso. Segundo ACKRÉ (1994), para este grupo mais vulnerável de crianças, o ideal é ser alimentado com o leite materno, independentemente do ambiente em que ele vive e de tecnologias ou fórmulas alternativas disponíveis, devido às inúmeras vantagens do leite materno em comparação a fórmulas lácteas.

O leite das mães de recém-nascidos prematuros tem composição diferente do leite das mães de $\mathrm{RN}$ a termo, apresentando maior valor calórico, maior concentração de proteinas, sódio e cloretos e menor de lactose. Os fatores de defesa como IgA, lactoferrina, lisosima, oligossacarídeos, fatores de crescimento e componentes celulares 
estão presentes em maior quantidade no leite de mães de prematuros e são fundamentais na proteção aos recém-nascidos que permanecem internados e expostos à flora bacteriana hospitalar (BRITO 1999).

Nas crianças BPN, a morbidade e mortalidade também são menos freqüentes entre os amamentados em comparação àqueles que consomem fórmulas lácteas (UNICEF 1981).

Em 1964, estudo clínico realizado em crianças prematuras mostrou que a amamentação logo após o nascimento é benéfica na redução da perda de peso e na recuperação mais rápida do peso de nascimento (SMALLPEICE e DAVIES 1964).

Em 1968, notou-se um melhor desenvolvimento intelectual e neurológico em RBPN que receberam leite materno precocemente (DAVIES e RUSSEL 1968).

O aleitamento materno nos primeiros seis meses de vida é um fator de proteção contra a anemia (SILVA e col. 2001). Isto porque, diferentemente do leite de vaca não modificado e das fórmulas infantis, o leite materno propicia à criança ferro de alta biodisponibilidade, o que é particularmente importante para os bebês BPN prematuros, os quais têm um risco maior de desenvolver anemia por deficiência de ferro devido aos estoques reduzidos do mineral associados ao nascimento precoce.

XAVIER e col. (1991), no entanto, referem que há dificuldade para a implementação do aleitamento materno nos recém-nascidos de baixo peso. Isto ocorre devido à dificuldade de se instituir, para este grupo especial, a assistência em alojamento conjunto, a permanência da mãe junto ao filho no período de internação da criança, o contato precoce mãe-filho, e a amamentação precoce, fatores tidos como significativos 
para o incentivo do aleitamento mesmo entre recém-nascidos a termo. Além disso, os RBPN, principalmente os prematuros, freqüentemente apresentam condições clínicas críticas, o que também se reflete em dificuldade na implementação do aleitamento.

Em estudo sobre a incidência e duração do aleitamento materno em recémnascidos de baixo peso, XAVIER e col. (1991) verificaram que a incidência e duração da amamentação foram menores do que entre crianças de maior peso. A incidência de aleitamento nas crianças BPN cujo peso ao nascer situa-se acima de $2000 \mathrm{~g}$ foi de 95,9\%; entre as crianças BPN de peso acima de $1500 \mathrm{~g}$ até $2000 \mathrm{~g}$ foi de $80,4 \%$, enquanto entre aquelas de muito baixo peso foi de $41,7 \%$. O tempo de aleitamento também diferiu entre os grupos de BPN: a duração do aleitamento materno foi de 2,5 meses para as crianças com peso ao nascer igual ou menor que $2000 \mathrm{~g}$, tempo que duplicou entre aquelas com peso ao nascer acima de $2000 \mathrm{~g}$.

Em estudo realizado em 111 municípios do Estado de São Paulo, VENANCIO (2002) destacou que o baixo peso ao nascer constitui fator de risco para a interrupção do aleitamento materno exclusivo.

Igualmente HORTA e col. (1996b), em estudo na cidade de Pelotas, Rio Grande do Sul, verificaram que crianças com baixo peso ao nascer apresentaram durações mais curtas de amamentação. Eles salientaram a necessidade de campanhas de incentivo ao aleitamento que priorizem crianças nascidas com baixo peso, que são as que mais necessitariam do aleitamento.

NARAYANAN (1986) afirma que o aleitamento materno para o recém nascido de baixo peso é um dever: "um passaporte para a vida". 
Após o sexto mês de vida, a fim de satisfazer as necessidades nutricionais da criança em crescimento, sua dieta deve ser complementada com outros alimentos. $\mathrm{O}$ processo ou período de transição durante o qual o leite materno é substituído progressivamente por uma dieta variada, baseada nos alimentos consumidos pela familia é denominado desmame (OMS/UNICEF 1979).

O período de desmame é uma fase de transição que exige cuidados, tanto pela possibilidade de administração de alimentos inadequados, quanto pelo risco de contaminação, favorecendo a ocorrência de diarréia e desnutrição (SPOLIDORO e MÜLLER 2001).

Assim como a introdução precoce da alimentação complementar pode trazer prejuízos à criança, o início tardio do desmame também pode trazer conseqüências negativas, tais como déficit de crescimento e desnutrição. Estudo da OMS (WHO 1981) revelou que nos grupos com baixos níveis de complementação após a idade de 6 meses, a taxa de crescimento dos lactentes reduziu-se para um nível muito abaixo da referência para essa idade.

A amamentação exclusiva durante os primeiros meses, a complementação adequada e oportuna e a continuação do aleitamento materno pelo tempo necessário para assegurar a sua substituição por uma dieta nutritiva e sem riscos para o recémdesmamado são medidas importantíssimas para the assegurar um crescimento e desenvolvimento adequados.

Com base no exposto, fica evidente a importância do aleitamento materno na alimentação do infante, bem como da introdução adequada de alimentos 
complementares, especialmente para as crianças nascidas com baixo peso, para garantir um princípio de vida sadio.

Outro fator de grande importância quando se trata de crianças nascidas com baixo peso é o seu crescimento e desenvolvimento, principalmente nos primeiros meses de vida. Após o nascimento, o desaparecimento da condição de privação intra-uterina característica das crianças nascidas com retardo de crescimento intra-uterino (RCIU) pode levar a um rápido crescimento recuperacional, em condições adequadas de saúde e nutrição. Por outro lado, as condições que levaram ao RCIU, se permanecerem, certamente determinarão outras privações durante os primeiros meses de vida, quando se esperaria uma reversão do retardo intra-uterino. $\mathbf{O}$ monitoramento do processo de crescimento é, portanto, fundamental para as crianças nascidas de baixo peso.

Igualmente importante é o conhecimento do estado nutricional da criança BPN. Em crianças, os índices antropométricos mais freqüentemente utilizados são o peso/idade, o comprimento/idade e o peso/comprimento. Esses indices são obtidos comparando-se as informações de peso, comprimento, idade e sexo com curvas de referência, como a do National Center for Health Statistics (NCHS), padrão internacional recomendado pela Organização Mundial da Saúde (WHO, 1986). Os resultados assim obtidos são expressos como escores $Z$, percentis ou percentuais da mediana. A Organização Mundial da Saúde (OMS), sugere que se utilize como indicadores de desnutrição as proporções de crianças com índices inferiores a -2 escores Z. 
Os índices antropométricos acima mencionados refletem processos diferentes. $\mathrm{O}$ indice peso para idade $(\mathrm{P} / \mathrm{I})$ reflete a massa corporal em relação à idade cronológica. Esse índice é principalmente uma composição do peso/comprimento $(\mathrm{P} / \mathrm{C})$ e do comprimento/idade (C/I); desta forma, o baixo $\mathrm{P} / \mathrm{I}$ pode refletir o baixo $\mathrm{C} / \mathrm{I}$, o baixo $\mathrm{P} / \mathrm{C}$ ou ambos . $\mathrm{O}$ índice comprimento para idade $(\mathrm{C} / \mathrm{I})$ reflete o desempenho do crescimento linear alcançado e seu déficit indica deficiências acumuladas de saúde ou desnutrição ao longo do tempo. O baixo comprimento para a idade pode refletir uma variação normal ou um processo patológico. Sendo patológico, reflete o fracasso em alcançar o potencial de crescimento linear como resultado de condições sanitárias e nutricionais desfavoráveis. Em crianças menores (até 3 anos), o baixo $\mathrm{C} / \mathrm{I}$ reflete um processo contínuo de "não crescer" ou de retardo de crescimento ("stunting"), enquanto nas crianças maiores, reflete o estado de não haver crescido ou sofrer os efeitos do retardo do crescimento ("stunted"). O peso para comprimento $(\mathrm{P} / \mathrm{C})$ reflete o peso corporal em relação à comprimento. $\mathrm{O}$ baixo peso para comprimento reflete um processo grave e recente que levou a uma perda considerável de peso, em geral como conseqüência de fome aguda e/ou de uma doença grave (WHO, 1995).

Mais um aspecto que deve ser ressaltado ao se tratar de crianças nascidas de baixo peso é o fato de o BPN constituir-se em um fator predisponente muito importante na gênese da anemia ferropriva. A ocorrência da anemia na infância é determinada pela velocidade de crescimento da criança e pelas reservas de ferro ao nascimento. A tendência a um crescimento acelerado, característica da criança BPN, leva a um esgotamento mais precoce do ferro endógeno e aumento do risco de anemia por 
deficiência do mineral. A reserva de ferro, acumulada na vida intrauterina, é proporcional ao peso de nascimento; assim, quanto menor o peso ao nascer, mais baixa é a quantidade de ferro orgânico (UCHIMURA e col. 2003). Desta forma, as conseqüências deletérias da anemia incidirão com maior freqüência sobre as crianças nascidas com baixo peso. A anemia na infância traz prejuizos para o desenvolvimento cognitivo e motor, para o crescimento e para o futuro aproveitamento escolar, e constitui-se em um importante problema de saúde pública (FURUMOTO \& SZARFARC 2001; SILVA e col. 2001).

Assim, novamente a alimentação adequada aparece como o fator mais importante na determinação do estado nutricional no que se refere ao crescimento e à situação de ferro orgânico.

Justifica-se assim, mais uma vez, a necessidade de atenção especial para este grupo mais vulnerável de crianças, não somente em relação à alimentação e ao crescimento, mas também ao risco de anemia, pelos efeitos deletérios que esta desnutrição acarreta.

O conhecimento da prática alimentar, dos padrões de crescimento, do estado nutricional e dos níveis de hemoglobina, no primeiro ano de vida, de crianças nascidas com baixo peso, poderá fornecer instrumentos para a adoção de práticas que conduzam à melhoria das condições de saúde deste grupo populacional.

Considerando o exposto e o significado do peso ao nascer para a evolução da criança, o presente trabalho teve por objetivo estudar a prática alimentar, o crescimento, 
o estado nutricional e a concentração de hemoglobina, em crianças nascidas com baixo peso atendidas em serviços públicos de saúde de cidades brasileiras. 


\section{OBJETIVOS}

\subsection{Objetivo Geral}

Identificar a prática alimentar, estado nutricional, velocidade de crescimento e concentração de hemoglobina, segundo idade, em crianças menores de um ano, nascidas com baixo peso, atendidas em serviços públicos de saúde.

\subsection{Objetivos Específicos}

- Conhecer a prática alimentar das crianças nascidas com baixo peso;

- Avaliar o estado nutricional;

- Analisar a velocidade de crescimento;

- Descrever a concentração de hemoglobina. 


\section{METODOLOGIA}

O presente trabalho faz parte de um estudo mais amplo intitulado "Aleitamento materno, dieta de desmame e anemia no primeiro ano de vida, em crianças atendidas na rede pública de saúde no Brasil", coordenada por Sônia Buongermino de Souza e Sophia Cornbluth Szarfarc, do Departamento de Nutrição da Faculdade de Saúde Pública da Universidade de São Paulo (USP) e financiada pela Fundação de Apoio à Pesquisa do Estado de São Paulo (FAPESP).

Trata-se de um estudo descritivo, com obtenção de dados de forma transversal, realizado com crianças menores de um ano de idade, que compareceram a serviços básicos de saúde selecionados nas cinco regiões geográficas brasileiras, para consulta de puericultura. Estabeleceu-se o número mínimo de 500 crianças por região geográfica, garantindo-se, pelo menos, 75 crianças por trimestre de vida. A amostra final foi composta por 5914 crianças provenientes de diferentes municípios brasileiros.

\subsection{Amostra e local de estudo}

A amostra estudada foi constituída por 536 crianças, com peso de nascimento inferior a $2500 \mathrm{~g}$, correspondendo a $9,06 \%$ da amostra inicial. Participaram do estudo exclusivamente crianças atendidas nos serviços de saúde para consultas de rotina e/ou vacinações. 
Os dados foram levantados entre novembro de 1997 e agosto de 1998, em serviços públicos de saúde de cidades selecionadas das cinco regiões geográficas brasileiras: Manaus (AM), Rio Branco (AC), Salvador (BA), Teresina (PI), Brasília (DF), Cuiabá (MT), Rio de Janeiro (RJ), São Paulo (SP), Santo André (SP), Viçosa (MG), Maringá (PR) e Porto Alegre (RS).

A escolha dos locais vinculou-se à existência de pesquisadores na área de nutrição, ligados a universidades ou a institutos de pesquisa que aceitaram participar do estudo. Os serviços de saúde foram escolhidos pelos coordenadores responsáveis pela pesquisa em cada cidade, sendo, geralmente, centros de saúde de grande demanda, em que eram realizados estágios de alunos de cursos de nutrição, enfermagem e medicina.

\subsection{Aspectos éticos}

A pesquisa foi aprovada pelos Comitês de Ética da Faculdade de Saúde Pública da Universidade de São Paulo e dos Serviços de Saúde onde foi aplicado, tendo ainda a concordância formal da mãe ou responsável pela criança para sua participação no estudo.

\subsection{Coleta de dados}

Após o consentimento das mães ou responsáveis pela criança para participação na pesquisa (anexo 1), era preenchido um formulário (anexo 2), do qual foram 
analisados, para o presente estudo, os dados referentes à idade, peso, comprimento, concentração de hemoglobina e alimentação da criança.

A coleta dos dados foi realizada, em algumas localidades, por atendentes de enfermagem dos serviços de saúde, e em outras por alunos, bolsistas e/ou estagiários dos cursos, após treinamento, sob a supervisão direta dos coordenadores.

\subsubsection{Inquérito Alimentar}

A prática alimentar foi obtida pelo método status quo, ou seja, um estudo transversal em que se investiga a idade de cada criança e sua relação com o evento de interesse no momento da pesquisa. Consta do formulário uma lista de alimentos mais utilizados no primeiro ano de vida. Para cada alimento, a resposta, quanto ao consumo, foi sim ou não.

\subsubsection{Inquérito Antropométrico}

Os dados de peso e comprimento ao nascer foram obtidos do cartão da maternidade, apresentado no momento da matrícula no serviço de saúde, e constantes da folha de protocolo da criança.

O peso e comprimento atuais (no momento da entrevista) foram obtidos das medidas feitas rotineiramente nos serviços de saúde, na consulta de puericultura. 


\subsubsection{Dosagem de Hemoglobina}

A dosagem da concentração de hemoglobina foi feita em sangue capilar colhido por puntura digital ou do calcanhar, utilizando-se o fotômetro portátil Hemocue para leitura. Este equipamento é recomendado pela OMS para investigações populacionais sobre prevalência de anemia devido à imediata obtenção do resultado e à utilização de pequeno volume sanguíneo.

O resultado da medida era imediatamente comunicado à mãe e ao serviço de saúde, que se encarregava de orientar e intervir, sempre que necessário.

\subsection{Variáveis de estudo}

\subsubsection{Variáveis maternas}

- Idade materna

- Escolaridade materna

\subsubsection{Variáveis da criança}

- Sexo

- Idade

- Peso ao nascer

- Prática alimentar

- Estado nutricional 
- Velocidade de crescimento

- Concentração de hemoglobina

\subsection{Categorização das variáveis}

- Idade materna:

- <20 anos: mães adolescentes

- 20 a 34 anos: mães em idade reprodutiva ótima

- $\quad 35$ anos e mais: mães maduras

- Escolaridade materna:

- nenhuma: mães analfabetas

- 1 a 4 anos: mães com baixa escolaridade

- $\quad 5$ a 8 anos: mães com média escolaridade

- $\quad 9$ anos e mais: mães com alta escolaridade

- Sexo:

- masculino

- feminino

- Idade: em meses, determinada pela diferença entre o dia de nascimento e o dia da entrevista, dividida por 30,41

- Peso ao nascer:

- $\quad<1000 \mathrm{~g}$ : extremo baixo peso ao nascer

- $\quad 1000$ - $1499 \mathrm{~g}:$ muito baixo peso ao nascer

- $\quad 1500-2499 \mathrm{~g}$ : baixo peso ao nascer 
- Prática alimentar:

1. Alimentação láctea:

Considerando-se a somente o tipo de leite ingerido, independentemente de a criança estar recebendo alimentos complementares, dividiu-se a dieta em:

- leite materno: quando o leite materno era o único alimento lácteo recebido pela criança;

- leite misto: quando leite materno e não materno eram ingeridos pelo lactente;

- leite não materno: quando o leite não materno era o único alimento lácteo recebido pela criança;

- nenhum: quando a criança não recebia leite materno nem leite não materno.

2. Alimentação complementar

Verificou-se a proporção de crianças que consumiam alimentos de cada uma das seguintes categorias:

- Água e/ou chá;

- Leite não materno;

* Açúcar;

- Frutas: em forma de sucos ou papas;

* Legumes: tomate, cenoura, beterraba etc.

* Verduras: alface, couve, espinafre etc.

* Raízes e tubérculos: batata, cará, mandioca, batata-doce etc.

* Cereais e derivados: arroz, fubá, macarrão, pão e/ou bolacha;

- Carnes: bovina, de frango ou outras aves, figado, peixe; 
* Caldo de carne;

* Feijão ou caldo de feijão;

* Ovos: gema ou ovo inteiro.

\section{Aleitamento materno}

Quanto à prática do aleitamento, as crianças foram enquadradas nas categorias descritas a seguir, com base em proposta da UNICEF (1995), acrescentando-se as categorias "sem aleitamento materno" e "sem leite":

* Aleitamento materno exclusivo (AME) - ingestão somente de leite materno, sem nenhum outro alimento líquido ou sólido, com exceção de suplementos vitamínicos, minerais ou medicamentos.

* Aleitamento materno predominante (AMP) - ingestão de leite materno, água, chás, suco de frutas, sem outros tipos de leite ou alimentos sólidos.

* Aleitamento materno (AM) - ingestão de leite materno e qualquer outro tipo de alimento, mesmo outros tipos de leite.

* Sem aleitamento materno (SAM) - ingestão de leite não materno e outros alimentos que não o leite materno.

Sem leite (SL) - ingestão somente de alimentos não lácteos.

- Estado nutricional

O estado nutricional foi avaliado através dos seguintes indicadores antropométricos:

- $\quad$ peso $(\mathrm{kg}) /$ idade (meses); 
- $\quad$ peso $(\mathrm{kg}) /$ comprimento $(\mathrm{cm})$;

- comprimento (cm) /idade (meses).

Estes indicadores foram classificados em escore $Z$, de acordo com o padrão de referência do National Center for Health Statistics (NCHS).

Classificaram-se como desnutridas todas as crianças que apresentassem valores de escores $\mathrm{Z}$ abaixo de -2 , e como obesas as crianças cujo peso para comprimento estivesse acima de dois escores $\mathrm{Z}$.

Os índices antropométricos foram calculados através do módulo "Epinut antropometry" versão 6.0 4b do pacote estatístico Epi Info 1994.

Crianças com valores aberrantes de peso e/ou comprimento foram excluídas da análise. Para tanto, de acordo com recomendações do comitê de especialistas da Organização Mundial da Saúde (OMS), e empregando a distribuição de referência NCHS, foram excluídas as crianças classificadas em pelo menos uma das seguintes condições: peso inferior ou superior a 5 desvios-padrão da mediana esperada para idade e sexo; comprimento inferior a 5 desvios-padrão ou superior a 3 desvios-padrão da mediana esperada para idade e sexo e peso inferior a 4 desvios-padrão ou superior a 5 desvios-padrão da mediana esperada para a comprimento e sexo.

\section{- Velocidade de crescimento}

A velocidade de crescimento foi obtida subtraindo do valor do score $Z$ de peso atual da criança, calculado com base nos valores de referência do NCHS, o valor do score Z do peso de nascimento. 
Foram criadas três categorias:

velocidade de crescimento $<-1$ : crescimento inferior ao esperado;

velocidade de crescimento entre -1 e +1 : crescimento com velocidade esperada;

* velocidade de crescimento $>+1$ : crescimento acima do esperado.

- Concentração de hemoglobina

Devido à não existência de valores padronizados para a identificação da anemia no primeiro semestre de vida, optou-se por não classificar as crianças em anêmicas ou não anêmicas, mas verificar a proporção de crianças com hemoglobina inferior a $11 \mathrm{~g} / \mathrm{dL}$, padrão proposto pela OMS para crianças no segundo semestre de vida.

Verificou-se também a concentração média de hemoglobina por idade (em meses), bem como a concentração média de hemoglobina segundo o consumo de alimentos fontes de ferro e o tipo de leite ingerido.

\subsection{Análise Estatística}

Para a análise dos dados foi utilizado o programa estatístico Epi Info 6 (DEAN e col. 1994).

Os resultados foram descritos por meio de médias, desvios-padrão, medianas e proporções. Considerou-se valor de $\mathrm{p}<0,05$ para significância. 


\section{RESULTADOS E DISCUSSÃO}

\subsection{Caracterização da amostra}

A amostra do estudo foi constituída por 536 crianças nascidas de baixo peso, que representaram $9,06 \%$ da população estudada, que freqüentava os serviços de saúde participantes da pesquisa. É importante lembrar que estas crianças freqüentaram os serviços de saúde para consultas de rotina, não apresentando sinais e/ou sintomas de problemas de saúde.

Proporção semelhante de baixo peso ao nascer foi encontrada na Pesquisa Nacional sobre Demografia e Saúde (PNDS) (IBGE 1997), de 1996, que foi um inquérito de base domiciliar, realizado em âmbito nacional, nos meios urbano e rural, com crianças menores de cinco anos, que revelou proporção de BPN de 9,2\%.

Em estudo colaborativo de âmbito nacional, restrito às maternidades das capitais brasileiras, NÓBREGA (1995) encontrou incidência de BPN pouco inferior, igual a $8,3 \%$.

$\mathrm{Na}$ amostra estudada, o menor valor de peso ao nascer encontrado foi de $760 \mathrm{~g}$. Os pesos médios e medianos ao nascer foram, respectivamente, $2140 \mathrm{~g}(\mathrm{dp}=339 \mathrm{~g}) \mathrm{e}$ $2250 \mathrm{~g}$.

A figura 1 apresenta a classificação das crianças deste estudo segundo categorias de peso ao nascer. 
Nota-se que a maior parte das crianças enquadra-se na categoria de peso acima de 1500 g. Isto é esperado porque o peso ao nascer é uma variável que está diretamente associada à possibilidade de sobrevivência do recém-nascido, sendo o baixo peso ao nascer um fator de risco para a mortalidade neonatal e perinatal (PUFFER e SERRANO 1973), principalmente quando se trata de recém-nascidos de muito baixo peso e extremo baixo peso. Por isto é incomum sua presença nos serviços de puericultura.

Figura 1 - Distribuição do número de crianças segundo peso ao nascer.

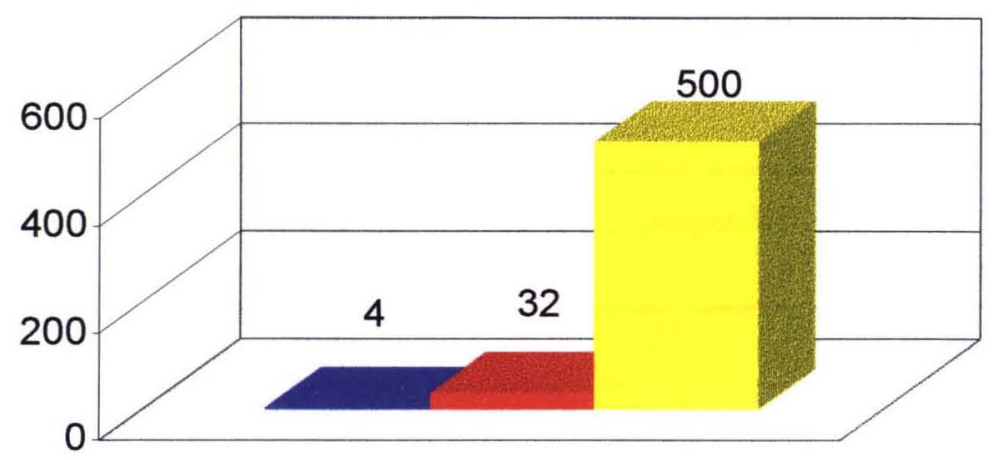

E extremo baixo peso muito baixo peso baixo peso

Observou-se na amostra estudada uma predominância de crianças do sexo feminino $(56,3 \%)$, proporção que difere da encontrada para aquelas que não nasceram com baixo peso, em que predominam crianças do sexo masculino $(52,1 \%)$, sendo esta diferença estatisticamente significante $(\mathrm{p}<0,05)$. Tal distinção pode ser explicada pelo fato do peso ao nascer, para os meninos, ser normalmente maior do que para as meninas. 
A idade mínima encontrada na amostra de crianças BPN foi de 6 dias. A média de idade foi de 177 dias $(\mathrm{dp}=95)$ e a mediana, de 174 dias.

Ao se comparar a idade das crianças nascidas de baixo peso com a idade de todas as crianças do estudo (Tabela 1), verificou-se que, no primeiro trimestre, a proporção de crianças BPN em relação ao total é menor do que a proporção nos outros três trimestres, sendo esta diferença estatisticamente significativa $(p<0,05)$. Isso possibilita acreditar que as crianças BPN iniciam mais tardiamente a procura pelos serviços de saúde para as consultas de rotina.

Tabela 1 - Distribuição das crianças BPN em relação ao número total de crianças, segundo idade (meses)

\begin{tabular}{cccc}
\hline Idade (meses) & $\begin{array}{c}\mathbf{N}^{\mathbf{0}} \text { de crianças } \\
\text { estudadas }\end{array}$ & $\mathbf{N}^{\mathbf{0}}$ de crianças BPN & \% de crianças BPN \\
\hline 0 & 311 & 21 & 6,75 \\
\hline 1 & 583 & 50 & 8,57 \\
\hline 2 & 614 & 44 & 7,17 \\
\hline 3 & 582 & 65 & 11,17 \\
\hline 4 & 669 & 50 & 7,47 \\
\hline 5 & 545 & 50 & 9,17 \\
\hline 6 & 533 & 40 & 7,50 \\
\hline 7 & 460 & 60 & 13,04 \\
\hline 8 & 429 & 45 & 9,48 \\
\hline 9 & 496 & 49 & 10,65 \\
\hline 10 & 338 & 36 & 7,34 \\
\hline 11 & 354 & 26 & 9,06 \\
\hline Total & 5914 & 536 & \\
\hline
\end{tabular}


As localidades em que se encontrou maior proporção de crianças nascidas com baixo peso nos serviços de saúde foram Salvador, Rio de Janeiro e Santo André (Tabela 2). Considerando-se as cinco regiões geográficas brasileiras, encontrou-se a maior proporção de BPN no Nordeste (11,3\%) e a menor, no Sul $(7,4 \%)$.

Estudo realizado pelo UNICEF (1994) mostrou que as condições desfavoráveis de sobrevivência infantil concentram-se na região Nordeste, sendo que nesta região é que estão presentes as maiores incidências de BPN.

Tabela 2 - Distribuição das crianças BPN em relação ao número total de crianças, segundo as cidades do estudo.

\begin{tabular}{lccc}
\hline \multicolumn{1}{c}{ Cidade } & $\begin{array}{c}\mathbf{N}^{\circ} \text { de } \\
\text { crianças } \\
\text { estudadas }\end{array}$ & $\begin{array}{c}\mathbf{N}^{\mathbf{0}} \text { de crianças } \\
\text { BPN }\end{array}$ & \% de crianças BPN \\
\hline Salvador & 295 & 40 & 13,60 \\
Rio de Janeiro & 498 & 57 & 11,44 \\
Santo André & 1311 & 132 & 10,06 \\
Rio Branco & 342 & 31 & 9,06 \\
São Paulo & 155 & 14 & 9,03 \\
Teresina & 378 & 34 & 8,99 \\
Porto Alegre & 433 & 37 & 8,54 \\
Cuiabá & 385 & 32 & 8,31 \\
Viçosa & 361 & 29 & $\mathbf{8 , 0 3}$ \\
Manaus & 563 & 45 & 7,99 \\
Brasília & 610 & 48 & 7,86 \\
Maringá & 583 & 37 & 6,34 \\
\hline Total & 5914 & 536 & 9,06 \\
\hline
\end{tabular}


A idade materna média das crianças de baixo peso ao nascer foi de 24,3 anos $(\mathrm{dp}=6,6)$, variando de 14 a 47 anos. A mediana de idade foi de 23 anos.

Ao se comparar a idade materna das crianças BPN com a idade materna daquelas que não nasceram de BP (Figura 2), observou-se uma maior proporção de mães adolescentes e de mães maduras entre as crianças de baixo peso ao nascer, verificandose para este grupo populacional um total de $39,1 \%$ de mães nos extremos da idade reprodutiva, contra $29,9 \%$ para as demais crianças, diferença estatisticamente significativa $(\mathrm{p}<0,05)$.

Figura 2 - Distribuição da porcentagem de crianças de baixo peso ao nascer e não baixo peso ao nascer segundo a idade materna* .

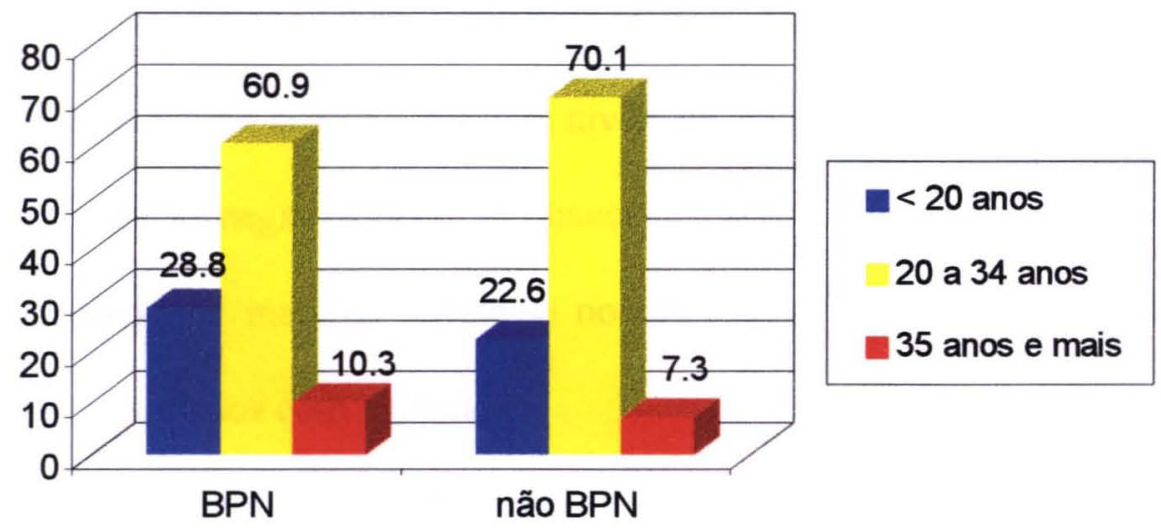

*excluídos 16 indivíduos sem informação

VICTORA e col. (1989), estudando recém-nascidos de hospitais da cidade de Pelotas, no ano de 1982, igualmente verificaram maior ocorrência de baixo peso ao nascer entre as mães menores de vinte anos e com mais de quarenta anos. 
A maior proporção de mães jovens e de mães maduras encontrada entre as crianças nascidas de baixo peso pode ser explicada pelo fato de que baixas e elevadas idades maternas podem ser fatores de risco para a prevalência dessa ocorrência (ALMEIDA e MELLO JORGE 1998; ALMEIDA 1995; BARROS e col. 1992; KRAMER 1987).

A associação entre a baixa idade materna e a prevalência de baixo peso ao nascer deve-se a fatores biológicos como imaturidade ginecológica e a fase de crescimento das adolescentes. A gestação na adolescência constitui-se em um problema de saúde pública que traz conseqüências não somente ao recém-nascido, resultando em maior mortalidade neonatal e perinatal, mas para as próprias adolescentes, devido às repercussões que a gravidez precoce pode trazer ao seu desenvolvimento psicológico e social, podendo representar um obstáculo ao acesso a maiores níveis de escolaridade, o que, por sua vez, também pode influenciar negativamente as chances de sobrevivência do recém-nascido, pois a baixa escolaridade materna reflete-se nos cuidados tidos durante a gestação e posteriormente nos cuidados com a criança.

Quanto à escolaridade materna, observou-se neste grupo populacional uma elevada proporção de mães com baixo grau de instrução já que a maior parte delas $(63,7 \%)$ possuía no máximo 4 anos de estudo. Verificou-se também ser maior a proporção de mães analfabetas do que de universitárias. A mediana de escolaridade materna foi de 3,5 anos. A escolaridade dos pais é pouco superior à das mães, sendo a mediana de escolaridade paterna de 4,7 anos. 
Os serviços públicos de saúde concentram a população de mais baixo nível socioeconômico e de escolaridade. Mesmo assim, chama a atenção a proporção de mães com baixo grau de instrução. Ao se considerar o conceito de analfabetismo funcional, que envolve os indivíduos que possuem até três anos de escolaridade, verificou-se que quase metade desta amostra $(48,3 \%)$ encaixa-se nesta condição.

A figura 3 mostra a escolaridade materna das crianças BPN e daquelas que não nasceram com baixo peso. Observou-se uma maior proporção de mães com baixa ou nenhuma escolaridade para o grupo de crianças nascidas com baixo peso, diferença estatisticamente significante $(\mathrm{p}<0,05)$.

Também VICTORA e col. (1989) observaram que a baixa escolaridade materna esteve associada com o BPN em recém-nascidos de Pelotas, visto que a proporção de nascimentos de baixo peso entre as mães sem nenhuma instrução foi o dobro daquela verificada entre as mães com nove ou mais anos de escolaridade.

Figura 3 - Distribuição da porcentagem de crianças de baixo peso ao nascer e não baixo peso ao nascer segundo a escolaridade materna** .

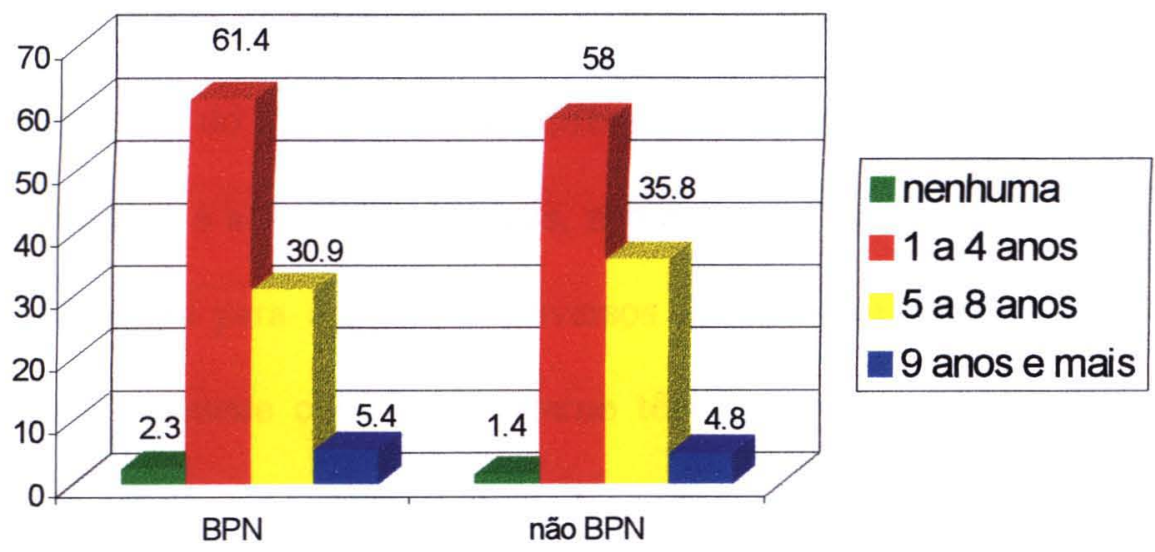

**excluídos 206 indivíduos sem informação 


\subsection{Prática alimentar}

A figura 4 mostra a situação da alimentação láctea da amostra estudada, considerando somente a especificidade do leite que estava sendo oferecido no momento da entrevista, independentemente de a criança estar recebendo ou não alimentos complementares.

Nota-se que, desde o primeiro mês de vida, é grande a proporção de crianças em aleitamento misto, o que significa que o desmame inicia-se precocemente e com leite não materno.

Pode-se observar que, após os seis meses, há uma queda acentuada do consumo de leite materno como único alimento lácteo, acompanhada por um aumento no consumo de leite não materno como único alimento lácteo, situação que se mantém até o final do primeiro ano de vida.

Cabe salientar que a introdução precoce de leite não materno associa-se a maior incidência de diarréias, infecções respiratórias, alergias e à presença de anemia. Deve-se também considerar a contaminação bacteriana do leite, ocasionada pelas manipulações sofridas até o momento do consumo, e as diferenças existentes entre a composição química do leite humano e a dos leites animais, não deixando dúvidas de que o leite de peito é o mais adequado para o lactente. Diversos estudos têm demonstrado que as crianças alimentadas somente com leite materno têm um melhor estado de saúde e menor risco de adoecer do que aquelas alimentadas com outros tipos de leite (VICTORA e col. 1987; HORTA e col. 1996b; WHO/UNICEF 1989). 
Figura 4 - Distribuição em porcentagem das crianças de baixo peso ao nascer segundo tipo de leite ingerido e idade (meses)***

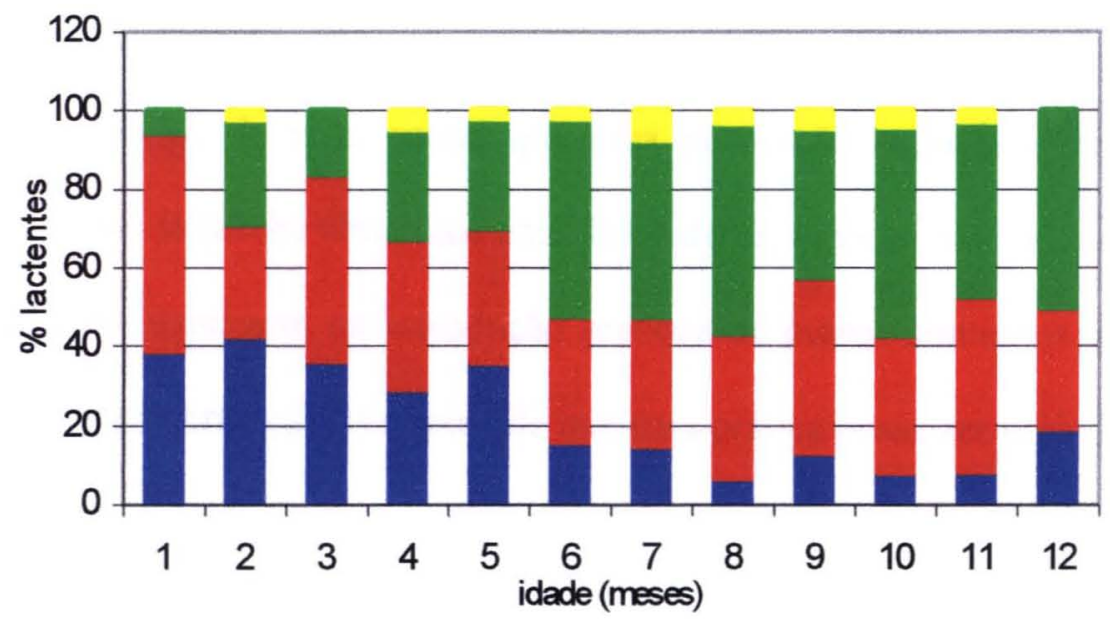

Leite de peito Leite misto Leite artificial Nenhum

*** excluídos 4 indivíduos sem informação

A tabela 3 apresenta a distribuição das crianças segundo a classificação proposta pelo UNICEF (1995) para a prática do aleitamento - acrescida das categorias "sem aleitamento materno (SAM)" (apenas leite artificial) e "sem leite (SL)" (materno ou artificial).

Considerando-se as crianças de até seis meses de idade, período para o qual a OMS (WHO 2001) recomenda aleitamento materno exclusivo, verificou-se que apenas $10,8 \%$ estavam nesta categoria; $11,9 \%$ estavam em aleitamento materno predominante, $46,7 \%$ em aleitamento materno, isto é, recebendo outros alimentos, lácteos ou não, além do leite materno; $28,2 \%$ não recebiam leite materno, mas sim outros tipos de leite, e $2,2 \%$ não recebiam nenhum tipo de alimento lácteo. Nesta pequena amostra de crianças que não recebia alimentos lácteos, verificou-se que grande parte delas $(83,3 \%)$ recebia 
água e/ou chá, e metade recebia frutas, cereais e derivados, caldo de feijão ou carne de frango. Com menor freqüência, foi observado o consumo de legumes, raizes e tubérculos, carne bovina e de figado e caldo de carne $(33,3 \%)$.

Observou-se, portanto, que não é freqüente a prática do aleitamento exclusivo nos primeiros seis meses de vida, sendo que uma proporção expressiva de crianças menores de seis meses já recebe alimentos complementares, embora não haja evidências de que exista alguma vantagem na introdução precoce de outros alimentos que não o leite humano na dieta da criança. Os relatos de que essa prática possa ser prejudicial, por outro lado, são abundantes. Chama a atenção a proporção considerável de crianças menores de seis meses que não é amamentada (30,4\%). A amamentação, especialmente nos primeiros meses de vida, é de grande importância especialmente para os recémnascidos de baixo peso, garantindo, em muitos casos, a sua sobrevivência.

Para as crianças maiores de seis meses, verificou-se que $0,8 \%$ estavam em aleitamento materno predominante, situação não desejável, já que a introdução tardia da alimentação complementar, conforme mencionado anteriormente, pode levar a desnutrição e déficit de crescimento. Observou-se que pouco mais da metade das crianças acima de seis meses não recebe leite de peito $(51,5 \%)$, situação esta distante da meta proposta pela OMS (WHO 2001) de se prolongar o aleitamento materno até pelo menos os dois anos de vida.

Entre as crianças maiores de seis meses que não recebiam alimentos lácteos, observou-se que a totalidade delas consumia água e/ou chá. Frutas e açúcar eram 
oferecidos a $60 \%$ destas crianças; faziam parte da papa salgada principalmente os legumes, raízes e tubérculos, cereais e derivados e caldo de feijão.

Tabela 3 - Distribuição porcentual das crianças segundo categoria de aleitamento e idade (meses). ${ }^{*}$

\begin{tabular}{ccccccc}
\hline $\begin{array}{c}\text { Idade } \\
\text { (meses) }\end{array}$ & $\mathbf{N}^{\mathbf{0}}$ & $\begin{array}{c}\text { AME } \\
(\%)\end{array}$ & $\begin{array}{c}\text { AMP } \\
\mathbf{( \% )}\end{array}$ & $\begin{array}{c}\text { AM } \\
\mathbf{( \% )}\end{array}$ & $\begin{array}{c}\text { SAM } \\
(\%)\end{array}$ & $\begin{array}{c}\text { SL } \\
(\%)\end{array}$ \\
\hline $0-3$ & 176 & 14,7 & 14,2 & 46,6 & 22,2 & 2,3 \\
\hline $4-5$ & 100 & 4,0 & 8,0 & 47,0 & 39,0 & 2,0 \\
\hline $6-11$ & 256 & 0,0 & 0,8 & 47,6 & 47,6 & 3,9 \\
\hline N total & $\mathbf{5 3 2}$ & $\mathbf{3 0}$ & $\mathbf{3 5}$ & $\mathbf{2 5 1}$ & $\mathbf{2 0 0}$ & $\mathbf{1 6}$ \\
\hline
\end{tabular}

*excluídas 4 crianças sem informação

A duração mediana de aleitamento exclusivo e predominante foi de 86 dias, e a duração mediana de aleitamento materno foi de 180 dias.

Considerando-se apenas as crianças inseridas na categoria "aleitamento materno" (AM), foi elaborada a tabela 4, que apresenta a distribuição destas crianças segundo o consumo de alimentos complementares.

Comprovou-se que uma grande proporção de crianças deste grupo recebia leite não materno ou água/chá logo nos primeiros meses de vida. No primeiro semestre, $79,8 \%$ destes lactentes já recebiam leite não materno e 73,6\% ingeriam água e/ou chá. É consenso, no entanto, que a complementação do leite materno com água ou chás nos primeiros seis meses de vida é desnecessária, inclusive em dias secos e quentes, e que o consumo precoce de leite de vaca é prejudicial à criança. 
Além disso, não é indicada a utilização de açúcar no primeiro ano de vida; no entanto, seu consumo é freqüente entre as crianças em $\operatorname{AM}(72,1 \%)$.

Tabela 4 - Distribuição porcentual das crianças em aleitamento materno (AM) segundo alimentação complementar e idade (meses).

\begin{tabular}{ccccccc}
\hline $\begin{array}{c}\text { Idade } \\
\text { (meses) }\end{array}$ & $\mathbf{N}^{\mathbf{0}}$ & $\begin{array}{c}\text { Leite } \\
\text { não } \\
\text { materno }\end{array}$ & $\begin{array}{c}\text { Papa } \\
\text { salgada }\end{array}$ & Frutas & Açúcar & Água/chá \\
\hline $0-3$ & 82 & 85,3 & 24,4 & 23,2 & 57,3 & 74,4 \\
\hline $4-5$ & 47 & 70,2 & 65,9 & 59,5 & 70,2 & 72,3 \\
\hline $6-11$ & 122 & 78,7 & 95,9 & 90,1 & 82,8 & 90,2 \\
\hline N total & $\mathbf{2 5 1}$ & $\mathbf{1 9 9}$ & $\mathbf{1 6 8}$ & $\mathbf{1 5 7}$ & $\mathbf{1 8 1}$ & $\mathbf{2 0 5}$ \\
\hline
\end{tabular}

O consumo de leite de vaca logo nos primeiros meses de vida e a adição de açúcar à água e/ou chá fazem do aleitamento materno exclusivo e do predominante práticas pouco freqüentes na população estudada, tornando o desmame uma prática precoce.

A complementação precoce é desvantajosa para a nutrição da criança, pois diminui o volume total do leite materno ingerido, reduz a duração do aleitamento materno e prejudica a absorção de nutrientes importantes existentes no leite materno, como o ferro e o zinco. Além disto, torna a criança mais vulnerável a infecções intestinais e respiratórias e desnutrição (WHO/UNICEF 1989; VICTORA e col. 1987).

A tabela 5 mostra que tipos de alimentos complementares são oferecidos às crianças sem aleitamento materno (SAM), isto é, aquelas que não consomem leite materno mas consomem outros tipos de leite. 
Verifica-se que o consumo de papa salgada, de frutas e de açúcar no primeiro semestre de vida é mais freqüente entre as crianças sem aleitamento materno (SAM) quando comparadas às crianças em aleitamento materno (AM), diferença estatisticamente significativa $(\mathrm{p}<0,05)$.

Tabela 5 - Distribuição porcentual das crianças sem aleitamento materno (SAM) segundo tipo de alimento consumido e idade (meses).

\begin{tabular}{cccccc}
\hline $\begin{array}{c}\text { Idade } \\
\text { (meses) }\end{array}$ & $\mathbf{N}^{\circ}$ & $\begin{array}{c}\text { Papa } \\
\text { salgada }\end{array}$ & Frutas & Açúcar & Água/chá \\
\hline $0-3$ & 39 & 25,6 & 30,7 & 76,9 & 64,1 \\
\hline $4-5$ & 39 & 76,9 & 64,1 & 74,3 & 76,9 \\
\hline $6-11$ & 122 & 97,5 & $\mathbf{8 8 , 5}$ & 94,6 & 72,9 \\
\hline N total & $\mathbf{2 0 0}$ & $\mathbf{1 5 9}$ & $\mathbf{1 4 5}$ & $\mathbf{1 7 4}$ & $\mathbf{1 4 4}$ \\
\hline
\end{tabular}

A tabela 6 apresenta a composição da papa salgada oferecida às crianças de BPN.

Observou-se que os alimentos mais comumente oferecidos são os legumes e as raízes e tubérculos, os quais são ingredientes da papa de sal de $77,9 \%$ e $84,5 \%$ das crianças, respectivamente, seguidos pelos cereais ou derivados, consumidos por $74,0 \%$ das crianças que ingerem papa salgada. A carne de frango é a carne mais consumida, seguida pela carne bovina. Entre as crianças que ingerem o almoço e/ou jantar, $67,2 \%$ inclui a carne de frango entre os ingredientes; $60 \%$ inclui a carne bovina. Fígado e peixe são pouco utilizados na composição da refeição: $37,0 \%$ e 34,9\%, respectivamente.

Verifica-se que $34 \%$ das crianças no primeiro semestre de vida já recebem alimentação de sal, prática que deveria ocorrer somente após os seis meses. Quanto às 
crianças maiores de seis meses, $94,1 \%$ consomem papa de sal, sendo que $52 \%$ destas já foram iniciadas no consumo de alimentos de todos os grupos, ou seja, cereais, legumes, verduras, carnes e leguminosas.

A alimentação complementar variada, além de garantir uma nutrição adequada para a criança, tem um papel fundamental na formação dos hábitos alimentares.

Tabela 6 - Distribuição porcentual das crianças segundo composição da alimentação salgada e idade (meses).

\begin{tabular}{|c|c|c|c|}
\hline \multirow{2}{*}{$\mathbf{N}^{\mathbf{0}}$ crianças $^{*}$} & \multicolumn{3}{|c|}{ Idade (meses) } \\
\cline { 2 - 4 } & $\mathbf{0 - 3}$ & $\mathbf{4 - 5}$ & $\mathbf{6} \mathbf{e}+$ \\
\hline $\mathbf{N}^{\mathbf{0}}$ com papa & 31 & 100 & 256 \\
\hline Cereais & 29,0 & 63 & 241 \\
\hline Legumes & 35,5 & 36,5 & 89,6 \\
\hline Verduras & 19,3 & 49,2 & 90,8 \\
\hline Raízes e tubérculos & 58,0 & 73,8 & 67,2 \\
\hline Feijão/caldo de & 74,2 & 87,3 & 90,8 \\
\hline feijão & 22,6 & 38,1 & 94,2 \\
\hline Carne bovina & 12,9 & 30,1 & 70,5 \\
\hline Caldo de carne & 16,1 & 17,5 & 41,9 \\
\hline Peixe & 19,3 & 46,0 & 78,8 \\
\hline Frango & 12,9 & 22,2 & 43,9 \\
\hline Fígado & 25,8 & 17,5 & 54,7 \\
\hline Ovos & & &
\end{tabular}

*excluídas 4 crianças sem informação 
Aos 191 dias e aos 197 dias de vida, metade das crianças já recebiam água/chá e leite não materno, respectivamente.

Quanto aos alimentos fontes de ferro, importantes na prevenção da anemia, verificou-se que, a partir dos 6 meses, a quase totalidade das crianças com papa salgada $(94,2 \%)$ recebia feijão e/ou caldo de feijão e a maior parte recebia carnes $(74,3 \%)$.

A tabela 7 apresenta a composição da alimentação salgada segundo o tipo de leite ingerido (leite materno, leite misto, leite não materno, nenhum). Pode-se observar que a freqüência de consumo da alimentação salgada aumenta do leite materno para o não materno, com diferença estatisticamente significativa $(p<0,05)$. 
Tabela 7 - Distribuição porcentual das crianças segundo composição da alimentação salgada e tipo de leite ingerido.

Leite materno

\begin{tabular}{|c|c|c|c|c|c|c|c|c|}
\hline $\begin{array}{c}\text { Idade } \\
\text { (meses) }\end{array}$ & $\begin{array}{c}\% \text { com } \\
\text { papa }\end{array}$ & Legumes & Verduras & Batata & Cereais & Carnes & Feijão & Ovos \\
\hline $\begin{array}{c}<=6 \\
\mathrm{~N}=89\end{array}$ & 19,1 & 35,3 & 11,7 & 35,3 & 29,4 & 29,4 & 94,1 & 5,8 \\
\hline $\begin{array}{c}>6 \\
\mathrm{~N}=28\end{array}$ & 89,2 & 84,0 & 68,0 & 96,0 & 100,0 & 88,0 & 92,0 & 60,0 \\
\hline
\end{tabular}

Leite misto

\begin{tabular}{|c|c|c|c|c|c|c|c|c|}
\hline $\begin{array}{c}\text { Idade } \\
\text { (meses) }\end{array}$ & $\begin{array}{c}\% \text { com } \\
\text { papa }\end{array}$ & Legumes & Verduras & Batata & Cereais & Carnes & Feijão & Ovos \\
\hline $\begin{array}{c}<=6 \\
\mathrm{~N}=103\end{array}$ & 33,0 & 55,8 & 35,3 & 76,4 & 44,1 & 52,9 & 76,4 & 26,4 \\
\hline $\begin{array}{c}>6 \\
\mathrm{~N}=96\end{array}$ & 94,8 & 94,5 & 54,9 & 86,8 & 96,5 & 81,3 & 91,2 & 59,3 \\
\hline
\end{tabular}

Leite não materno

\begin{tabular}{|c|c|c|c|c|c|c|c|c|}
\hline $\begin{array}{c}\text { Idade } \\
\text { (meses) }\end{array}$ & $\begin{array}{c}\text { \% com } \\
\text { papa }\end{array}$ & Legumes & Verduras & Batata & Cereais & Carne & Feijão & Ovos \\
\hline $\begin{array}{c}<=6 \\
\mathrm{~N}=78\end{array}$ & 51,3 & 37,5 & 45,0 & 75,0 & 22,5 & 47,5 & 82,5 & 20,0 \\
\hline $\begin{array}{c}>6 \\
\mathrm{~N}=122\end{array}$ & 97,5 & 89,0 & 76,4 & 93,2 & 86,5 & 87,4 & 96,6 & 49,5 \\
\hline
\end{tabular}




\subsection{Estado nutricional e velocidade de crescimento}

$O$ déficit $(-2$ escores $Z)$ para a relação peso/idade indica a ocorrência de desnutrição energético protéica. Encontrou-se, na amostra estudada, uma proporção de déficit de peso/idade de $15 \%$. Esta proporção é bastante superior àquela verificada entre as crianças que não nasceram com BP, que foi de $2,3 \%$.

Tal proporção é também maior do que a encontrada em inquéritos antropométricos realizados no país nos anos de 1989 e de 1996. O primeiro, de 1989, a Pesquisa Nacional de Nutrição e Saúde (PNSN), revelou uma prevalência de déficit peso/idade para crianças menores de dois anos de 7,2\%; enquanto o inquérito de 1996 , Pesquisa Nacional Sobre Demografia e Saúde (PNDS), obteve proporção de 4,9\% de desnutridos.

O déficit no indice peso/comprimento mede perda de peso recente, indicando desnutrição energético-protéica atual ("wasting"), enquanto o déficit comprimento/idade indica retardo de crescimento linear de longo prazo, isto é, quando o agravo nutricional ocorre por tempo prolongado, indicando desnutrição energético-protéica crônica ("stunting").

Encontrou-se na população estudada uma proporção de déficit peso/comprimento de $2,6 \%$, semelhante à encontrada para as outras crianças participantes do estudo, que foi de $2,1 \%$.

É aceito que prevalências em torno de $2,3 \%$ devam ser interpretadas como evidência de virtual ausência de desnutrição ou de obesidade na população, uma vez 
que, por definição, esse é o percentual esperado de índices antropométricos extremos em populações bem nutridas (MONTEIRO e CONDE 2000). Deste modo, a proporção de crianças com déficit peso/comprimento nesta amostra populacional ultrapassa apenas ligeiramente o percentual de $2,3 \%$ esperado pela distribuição de referência, evidenciando que a desnutrição indicada pelo emagrecimento extremo das crianças não é freqüente na amostra estudada, e ainda, indicando que as crianças de baixo peso ao nascer deste estudo estão se desenvolvendo satisfatoriamente.

Ainda, a proporção de déficit peso/comprimento encontrada nesta amostra é inferior à observada nos inquéritos antropométricos nacionais de 1989 e 1996, os quais encontraram, para menores de 24 meses, proporções de $3,1 \%$ e 3,2\%, respectivamente.

A proporção de déficit comprimento/idade encontrada na amostra de crianças BPN deste estudo foi igual a $30,6 \%$, indicando que o problema de maior magnitude para elas, quanto ao estado nutricional, é o "stunting". Na amostra de crianças não nascidas de baixo peso do estudo, esta proporção foi bastante inferior, igual a 5,8\%.

Os inquéritos PNSN e PNDS mostraram, entre as crianças menores de 24 meses de idade, déficit de comprimento/idade de $13,7 \%$ e $10,9 \%$, respectivamente, valores também bastante inferiores ao encontrado entre as crianças nascidas de BP estudadas.

Ao se comparar a população estudada com o padrão de referência do NCHS verifica-se que:

a distribuição dos valores de escore $Z$ do indice comprimento/idade apresenta um desvio para a esquerda, significando que as crianças deste estudo têm comprimento inferior às crianças do padrão de referência NCHS; 
a distribuição dos valores de escore $Z$ do índice peso/comprimento se assemelha à distribuição padrão;

a distribuição dos valores de escore $Z$ do índice peso/idade apresenta um desvio para a esquerda.

As crianças deste estudo, portanto, apresentam déficit de comprimento, indicativo de desnutrição crônica ou "stunting".

Esta forma de desnutrição, indicada pelo comprometimento severo do crescimento linear da criança, constitui, deste modo, o maior problema relativo ao estado nutricional da amostra em estudo, pela sua elevada frequêencia e também pelo amplo espectro de danos associados a essa condição: retardo do desenvolvimento psicomotor, dificuldade no aproveitamento escolar, diminuição da capacidade produtiva na idade adulta e aumento na incidência e severidade de enfermidades infecciosas. No caso das meninas, o retardo do crescimento na infância determina mulheres adultas de baixa comprimento sujeitas a um risco maior de gerar crianças com baixo peso ao nascer. Estas, por sua vez, terão um maior risco de apresentar retardo de crescimento e de produzir recém-nascidos de baixo peso, o que caracteriza o efeito intergerações da desnutrição (MONTEIRO e CONDE 2000).

Outro desvio nutricional relacionado à relação peso/comprimento é a obesidade, definida como excesso de peso para a comprimento superior a dois escores $\mathrm{Z}$. Encontrou-se, neste estudo, uma proporção de crianças obesas igual a $0,56 \%$, indicando, como esperado, que este não é um problema existente no estrato amostral estudado. Entre as crianças de não baixo peso ao nascer, essa proporção foi maior, igual a $8,0 \%$, 
mostrando que a tendência à obesidade observada na população adulta brasileira já é encontrada no primeiro ano de vida, mesmo entre a clientela de serviços públicos de saúde.

Os inquéritos de 1989 e 1996 também mostraram, para crianças menores de 24 meses, maiores prevalências de obesidade do que a verificada nas crianças BPN deste estudo, da ordem de $9,0 \%$ e $7,1 \%$, respectivamente.

A figura 5 apresenta a distribuição das crianças segundo a velocidade de crescimento por idade. Observa-se que, com exceção do primeiro mês, há um predomínio da categoria de velocidade de crescimento superior a 1. A maior parte das crianças $(63,7 \%)$, portanto, estava crescendo com velocidade acima do esperado. $36,1 \%$ das crianças apresentaram crescimento com velocidade esperada e apenas 1 criança, aos 11 meses de idade, apresentou crescimento inferior ao esperado.

A menor velocidade de crescimento observada no primeiro mês pode estar relacionada a modificações que ocorrem no período logo após o nascimento, relacionado à redução da água corpórea, caracterizando um período de perda de peso fisiológica.

Figura 5 - Distribuição em porcentagem das crianças de baixo peso ao nascer segundo velocidade de crescimento e idade (meses).

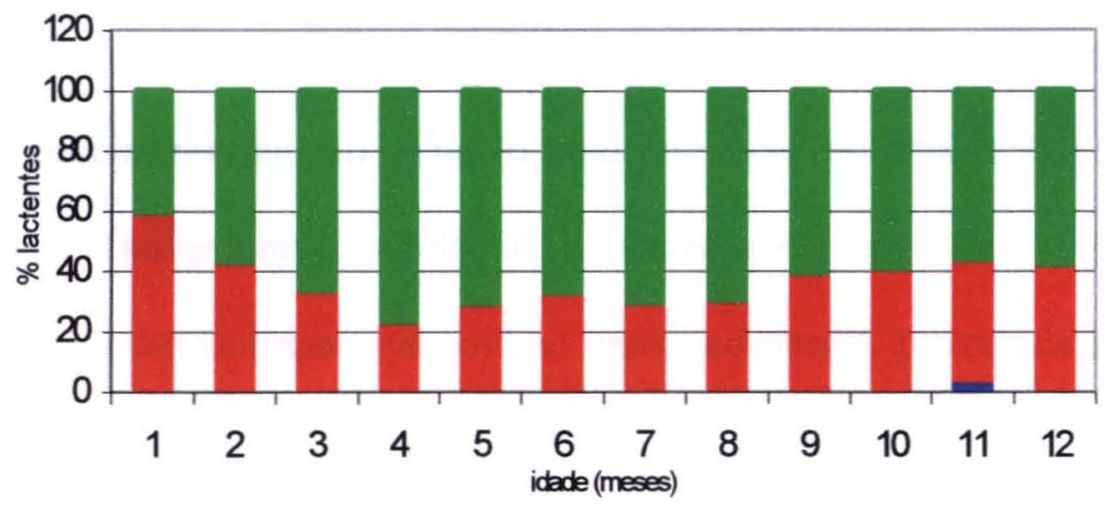

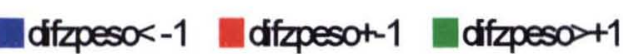


Observou-se que a velocidade de crescimento $>+1$ é mais freqüente entre as crianças de muito baixo peso ao nascer quando comparadas às de baixo peso ao nascer, pois apresentaram crescimento acima do esperado $93,3 \%$ das crianças de muito baixo peso ao nascer e $61,6 \%$ das crianças de baixo peso ao nascer, diferença estatisticamente significativa $(p<0,05)$.

Pode-se afirmar, portanto, que para a amostra de crianças deste estudo, a velocidade de crescimento relaciona-se com o peso de nascimento, sendo menor nas crianças de maior peso ao nascer, e que o crescimento ocorre com velocidade dentro ou acima da esperada para a quase totalidade das crianças.

É importante lembrar que a amostra deste estudo foi constituída exclusivamente por crianças atendidas nos serviços de saúde para consultas de rotina e/ou vacinações, não apresentando sinais e/ou sintomas de problemas de saúde. Elas não são representativas, portanto, do universo de crianças vivas nascidas de baixo peso.

\subsection{Concentração de Hemoglobina}

As crianças nascidas com baixo peso apresentam um risco aumentado de desenvolver anemia (SZARFARC e col. 2004). Sendo o estoque de ferro proporcional ao peso de nascimento, quanto menor o peso ao nascer mais baixa é a quantidade de ferro orgânico. Também sendo a velocidade de crescimento das crianças BPN maior do que a encontrada nas crianças com peso ao nascer adequado, a demanda pelo mineral é aumentada, levando a um esgotamento mais precoce do ferro endógeno. 
Conforme já mencionado, não estão ainda disponíveis valores críticos de hemoglobina para o diagnóstico de anemia de lactentes no primeiro semestre de vida, devido às rápidas mudanças de concentração de hemoglobina nesse período. No entanto, é aceito, na prática clínica, o valor de $11 \mathrm{~g} / \mathrm{dL}$ como referência para diagnóstico de anemia para este grupo populacional (SZARFARC e col. 2004), valor este proposto para os demais períodos de vida pela Organização Mundial da Saúde (OMS 1968).

A deteç̧ão da deficiência de ferro no primeiro ano de vida é de grande importância, porque representa um considerável agravo à saúde, por ser esta uma época de intenso crescimento e diferenciação das células cerebrais, podendo ocasionar prejuízos de aprendizagem, falta de atenção, sonolência, diminuição da acuidade mental, e ainda prejudicar o crescimento (SZARFARC e col. 2004).

No presente estudo, $73,7 \%$ das crianças apresentaram concentração de hemoglobina inferior a $11 \mathrm{~g} / \mathrm{dL}$, sendo que, destas, $62,2 \%$ apresentaram níveis de hemoglobina inferiores a 9,5 g/dL, considerado valor diagnóstico para anemia grave. As concentrações média e mediana de $\mathrm{Hb}$ encontradas foram, respectivamente, $9,65 \mathrm{~g} / \mathrm{dL}$ $(\mathrm{dp}=1,8)$ e $10,0 \mathrm{~g} / \mathrm{dL}$.

Comparando estes valores com aqueles encontrados entre as crianças que não nasceram com baixo peso, observou-se que, embora elevada, a prevalência de valores de hemoglobina inferiores a $11 \mathrm{~g} / \mathrm{dL}$ foi de $55,1 \%$, valor estatisticamente diferente do observado para as crianças de baixo peso ao nascer $(\mathrm{p}<0,05)$. A média de $\mathrm{Hb}$ encontrada para o grupo de não $\mathrm{BPN}$ foi de $10,52 \mathrm{~g} / \mathrm{dL}(\mathrm{dp}=1,92)$, superior à verificada para as crianças de BPN, sendo esta diferença também significativa estatisticamente $(p<0,05)$. 
A elevada proporção de crianças com valores baixos de concentração de hemoglobina encontrada na população de crianças BPN deste estudo evidencia a importância que o peso ao nascer exerce na ocorrência da anemia.

Consistente com este achado, encontram-se, na literatura, estudos que mostram a influência do baixo peso ao nascer no desenvolvimento dessa enfermidade. Em 1996, na área urbana do município de Criciúma (SC), NEUMAN e col. (2000) verificaram, pelo critério da OMS, $83,6 \%$ de anêmicos entre as crianças de baixo peso ao nascer. Considerando-se as crianças que não nasceram com BP, esta proporção, embora também elevada, foi bastante inferior, igual a $50,8 \%$.

No estado de São Paulo, TORRES e col. (1994), em estudo realizado entre crianças atendidas em unidades básicas de saúde, verificaram que a anemia atingiu mais aquelas que nasceram com baixo peso ou peso inadequado (inferior a 3000 gramas).

Ao estudar recém-nascidos de muito baixo peso ao nascer em uma maternidade de São Paulo, MARINO (2001) verificou que a anemia foi a afecção mais freqüente entre as crianças deste grupo, com uma prevalência de $75,6 \%$.

Em estudo sobre a prevalência de anemia em São Paulo, SZARFARC (1988) verificou ser o peso ao nascer um dos fatores etiológicos do estabelecimento desta enfermidade entre crianças de até cinco anos.

A figura 6 apresenta a curva de distribuição dos valores médios de concentração de hemoglobina da amostra estudada por idade. Pode ser verificado que, a partir do segundo mês de idade, as concentrações médias de hemoglobina encontram-se sempre 
abaixo de $11 \mathrm{~g} / \mathrm{dL}$, valor considerado como referência para detectar a baixa [Hb] nas crianças deste estudo.

Figura 6 - Concentração média de hemoglobina (média \pm dp) das crianças de baixo peso ao nascer por idade (meses).

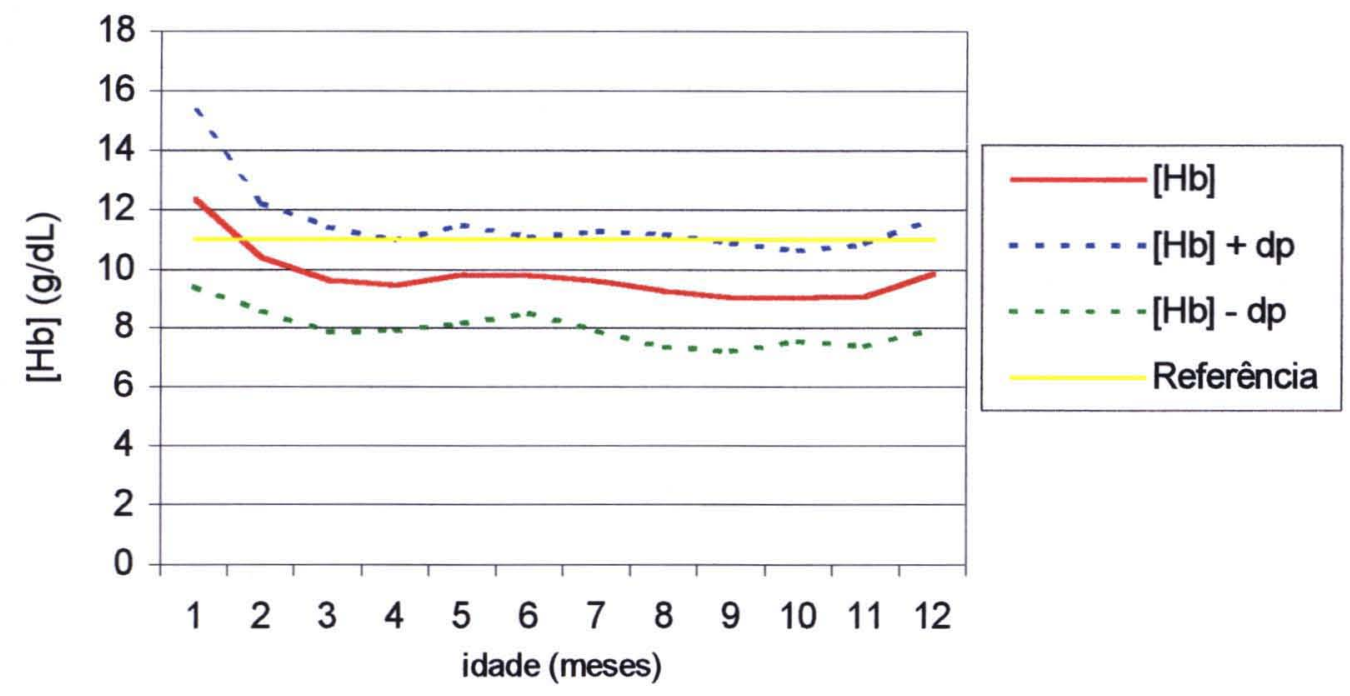

A tabela 8 apresenta a concentração média de hemoglobina das crianças com papa salgada $(n=335)$ considerando a ingestão referida de alimentos fontes de ferro: feijão + carnes, somente feijão, somente carne, e sem feijão/sem carne. Considerou-se o consumo de feijão como a ingestão do grão e/ou de seu caldo.

As diferenças observadas entre os grupos não foram estatisticamente significativas, para $\alpha=0,05$. 
Tabela 8 - Concentração média de hemoglobina ( $\mathrm{g} / \mathrm{dL})$ segundo consumo de alimentos fontes de ferro na papa de sal e idade (meses).

\begin{tabular}{cccccc}
\hline $\begin{array}{c}\text { Idade } \\
\text { (meses) }\end{array}$ & $\mathbf{N}$ & $\begin{array}{c}\text { Feijão }+ \\
\text { carnes }\end{array}$ & Feijão & Carnes & $\begin{array}{c}\text { Sem } \\
\text { feijão/ } \\
\text { Sem } \\
\text { carnes }\end{array}$ \\
\hline $0-3$ & 31 & 9,10 & 9,19 & 13,00 & 10,00 \\
\hline $4-5$ & 63 & 9,88 & 9,66 & 10,00 & 9,80 \\
\hline $6-11$ & 241 & 9,33 & $\mathbf{8 , 9 6}$ & 10,33 & $\mathbf{8 , 7 5}$ \\
\hline N Total & $\mathbf{3 3 5}$ & $\mathbf{2 3 9}$ & $\mathbf{6 6}$ & $\mathbf{1 0}$ & $\mathbf{2 0}$ \\
\hline
\end{tabular}

A tabela 9 apresenta a concentração média de hemoglobina de acordo com o tipo de leite ingerido. Observou-se que as crianças do grupo "leite materno" apresentaram [Hb] superior à dos grupos "leite misto" e "leite não materno", sendo esta superioridade estatisticamente significativa $(p<0,05)$, exceto para o grupo de crianças de $4-5$ meses quando se compara o grupo "leite materno" com "leite misto". No entanto, para este grupo de 4 - 5 meses, verificou-se diferença significante estatisticamente na $[\mathrm{Hb}]$ das crianças com "leite misto" em relação àquelas com "leite não materno" $(p<0,05)$, diferença que não foi observada nas idades de $0-3$ meses e de seis meses e mais.

O grupo de crianças que não consome nenhum alimento lácteo não foi incluído na análise devido ao pequeno tamanho da amostra $(n=16)$.

Pode-se afirmar que, para a amostra populacional deste estudo, os valores de hemoglobina relacionam-se com o tipo de leite ingerido, sendo maiores entre as crianças que consomem leite materno como único alimento lácteo. 
O consumo precoce de leite não materno, hábito este encontrado na maior parte da população de estudo (77,3\% das crianças consumiam outros tipos de leite), condiciona baixas reservas de ferro. O consumo de leite de vaca deve ser evitado no primeiro ano de vida, uma vez que, além de ser pobre em ferro, inibe a absorção deste mineral.

Os resultados encontrados ressaltam a grande proporção de crianças com concentração de hemoglobina inferior a $11 \mathrm{~g} / \mathrm{dL}$ nesta amostra de crianças BPN, principalmente entre aquelas que consomem leite não materno.

Tabela 9 - Concentração média de hemoglobina $(\mathrm{g} / \mathrm{dL})$ segundo tipo de leite ingerido e idade (meses)*

\begin{tabular}{cccccc}
\hline $\begin{array}{c}\text { Idade } \\
\text { (meses) }\end{array}$ & $\mathbf{N}$ & $\mathbf{L P}$ & $\mathbf{L M}$ & $\mathbf{L V}$ & Nenhum \\
\hline $0-3$ & 176 & 10,43 & 9,90 & 9,66 & 9,50 \\
\hline $4-5$ & 100 & 10,03 & 9,99 & 9,54 & 9,50 \\
\hline $6-11$ & 256 & 9,67 & 9,27 & 9,22 & 9,05 \\
\hline $\mathbf{N}$ total & $\mathbf{5 3 2}$ & $\mathbf{1 1 7}$ & $\mathbf{1 9 9}$ & $\mathbf{2 0 0}$ & $\mathbf{1 6}$ \\
\hline
\end{tabular}

*excluidas 4 crianças sem informação 


\section{CONCLUSÕES}

Os resultados obtidos neste estudo permitem identificar os maiores riscos de desnutrição e de anemia inerentes à criança nascida com baixo peso, mesmo em se tratando de crianças que freqüentam serviços de rotina de puericultura, sendo consideradas crianças saudáveis.

A desnutrição crônica, medida pelo déficit na relação comprimento/idade, ocorreu em $30,6 \%$ das crianças de BPN. Valores de hemoglobina inferiores a $11,0 \mathrm{~g} / \mathrm{dL}$ foram observados com freqüência ainda mais elevada: $73,7 \%$.

Verificou-se, quanto à alimentação, a pouca adesão ao aleitamento materno exclusivo nos primeiros seis meses de idade, conforme recomendações da Organização Mundial de Saúde (OMS). Observou-se que o desmame iniciava-se precocemente e com o consumo de água e/ou chá ou de leite não materno, prática que, conforme já descrito, pode ser prejudicial à saúde da criança.

Destaca-se também que uma proporção considerável de crianças menores de seis meses não era sequer amamentada $(30,4 \%)$. Conforme já destacado, o aleitamento materno é de grande importância, especialmente para as crianças nascidas de baixo peso.

A velocidade de crescimento, avaliada pela diferença entre os escores $Z$ do peso ao nascer e no momento do estudo, mostrou a forte tendência à recuperação nutricional das crianças BPN. Apenas uma criança apresentou uma velocidade de crescimento menor do que o esperado, sendo que $63,7 \%$ delas apresentaram, como desejável, velocidade superior ao esperado para crianças nascidas com peso igual ou maior que $2500 \mathrm{~g}$. 


\section{CONSIDERAÇÕES FINAIS}

Há que se destacar, mais uma vez, que a alimentação exerce um papel primordial na saúde dos lactentes, em especial daqueles nascidos de baixo peso. No entanto, a prática pouco comum do aleitamento materno exclusivo e do predominante e o desmame precoce observados neste grupo remetem à necessidade de uma orientação nutricional adequada às mães das crianças nascidas com baixo peso, ressaltando-se a importância que o aleitamento materno representa para elas no primeiro ano de vida, bem como a importância da introdução correta da alimentação complementar, e dos possíveis problemas decorrentes do consumo precoce do leite não materno, considerando ser esta uma população de maiores riscos de desenvolver anemia.

Além disso, a elevada proporção de mães adolescentes e de mães maduras encontrada nessa amostra de crianças mostra a necessidade de um atendimento pré-natal especial para estes grupos de mães, já que são eles os grupos de maiores riscos para o processo gravídico. Paralelamente a isto, o baixo nível de instrução materna encontrado mostra que o incentivo à educação formal mais ampla deve ser visto também como uma forma de inserção das mulheres em estratos de menores riscos de saúde. 


\section{REFERÊNCIAS}

Abdallah VOS, Gonçalves AL, Jorge SM, Oliveira S, Almeida LRS. Crescimento de recém-nascidos de muito baixo peso ao nascer alimentados com três diferentes tipos de leite durante os primeiros dois meses de vida. J. Pediatr. (Rio de J.) 1992; 68 (9/10): $319-27$.

Ackré J (1994). Alimentação infantil: bases fisiológicas. São Paulo: OMS/IBFAN/IS.

Almeida MF. Mortalidade neonatal em Santo André. Tese de Doutorado - Faculdade de Saúde Pública - Universidade de São Paulo, São Paulo, 1995.

Almeida MF \& Mello Jorge MH. Pequenos para a idade gestacional: uma análise de seus fatores de risco e sua importância na mortalidade neonatal. Rev. Saúde Públ. 1998; 32: $217-24$.

Anderson D. Nutrição no cuidado do bebê de baixo peso ao nascimento. In: Mahan L K, Escott-Stump S. Krause: Alimentos, Nutrição e Dietoterapia. Edição. São Paulo: Roca; 2002.

Barker DJP, Gluckman PD, Godfrey KM, Harding JE, Owens JÁ, Robinson JS. Fetal nutrition and cardiovascular disease in adult life. Lancet 1993; 341: 938 - 41 . 
Barros FC e col.. Comparison of the causes and consequences of prematurity and intrauterine growth retardation: a longitudinal study in Southern Brazil. Pediatrics 1992; 99: 238-44.

Bemfam/IBGE. Pesquisa nacional sobre demografia e saúde 1996. Rio de Janeiro, 1997.

Brito ASJ. Aleitamento materno e prematuridade. In: Nestlé. $5^{\circ}$ Curso Nestlé de Atualização em Pediatria [resumo]. Foz do Iguaçu: 1999. p.192 - 195.

Chaves SP. Crescimento e concentração de hemoglobina de lactentes em aleitamento materno exclusivo. São Paulo, 1999. [Tese de Doutorado - Faculdade de Saúde Pública da USP]

Davies PA \& Russel H. Later progress of 100 infants weighing 1000 to $2000 \mathrm{~g}$ at birth fed immediately with breast milk. Devel. Med. Child Neurol. 1968; 10: 725 - 735.

Dean AG e col.. Epi Info, VERSION 6.0. A Word Processing Database and Statistics Program for Epidemiology on Microcomputers. Center For Disease Control and Prevention, Atlanta, Georgia, USA, 1994. 
Ferraz EM, Gray RH, Cunha ATM. Determinants of preterm delivery and intrauterine growth retardation in North-East Brazil. Intern. J. Epidemiol. 1990; 19 (1): 101-8.

Franceschini SCC, Priore SE, Pequeno NPF, Silva DG, Sigulem DM. Fatores de risco para o baixo peso ao nascer em gestantes de baixa renda. Rev. Nutr. Campinas 2003; $16(2): 171-179$.

Freitas M. Recém-nascidos com peso de nascimento inferior a 2000 gramas: aspectos perinatais, neonatais e no primeiro ano de vida. São Paulo, 2001. [Dissertação de Mestrado - Faculdade de Saúde Pública da USP].

FUNDO DAS NAÇÕES UNIDAS PARA A CRIANÇA. FUNDAÇÃO INSTITUTO BRASILEIRO DE GEOGRAFIA E ESTATÍSTICA. Municípios brasileiros: crianças e suas condições de sobrevivência. (Censo demográfico de 1991). Brasília, 1994, 247 p.

Furumoto R; Souza M; Souza SB; Szarfarc SC. Estudo multicêntrico sobre aleitamento materno, dieta de desmame e anemia: dados de Brasília. In: Sociedade Brasileira de Alimentação e Nutrição. V Congresso Nacional da Sociedade Brasileira de Alimentação e Nutrição: nutrição, perspectivas para o próximo século; 1999 dez 58; São Paulo. São Paulo, SBAN, 1999. p. 157. 
Furumoto RV, Szarfarc SC, Souza SB. Anemia e peso ao nascer no primeiro ano de vida. FAISA, Santo André, SP [resumo]. In: Sociedade Brasileira de Alimentação e Nutrição. V Congresso Nacional da Sociedade Brasileira de Alimentação e Nutrição: nutrição, perspectivas para o próximo século. São Paulo, SBAN, 1999.

Furumoto R \& Szarfarc SC. Prevalência e duração do aleitamento materno em crianças atendidas na rede básica de saúde. In: Sociedade Brasileira de Alimentação e Nutrição. V Congresso Nacional da Sociedade Brasileira de Alimentação e Nutrição: nutrição, perspectivas para o próximo século; 1999 dez 5-8; São Paulo. São Paulo, SBAN, 1999. p. 192.

Furumoto R \& Szarfarc SC. Concentração de hemoglobina de menores de um ano atendidos nos serviços básicos de saúde de Santo André, SP, Brasil [resumo]. In: International Society of Pediatric Nutrition. III World Congress of Pediatric Nutrition: anais. São Paulo, Sociedade Brasileira de Pediatria/Nestlé, jul. 2001.

Gillespie S, Flores R. (2000). The life cicle of malnutrition. IFPRI $1999-2000$ Annual Report Essay (General Information). Washington DC: International Food Policy Research Institute. p. 8 -13. 
Giugliani ERJ, Victora CG. Normas alimentares para crianças brasileiras menores de dois anos: bases científicas. Brasilia: Organização Panamericana da Saúde; 1997. (OPAS/BRA/OCD/006).

Horta BL, Barros FC, Halpern R, Victora CG. Baixo peso ao nascer em duas coortes de base populacional no Sul do Brasil. Cad. Saúde Públ. 1996a; 12 (1 Supl): 27-31.

Horta BL, Olinto MTA, Victora CG, Barros FC, Guimarães PRV. Amamentação e padrões alimentares em crianças de duas coortes de base populacional no sul do Brasil: tendências e diferenciais. Cad. Saúde Públ. 1996b; 12 (1 Supl): 43 - 8.

Joaquim MC, Lima LA, Silva MB, Oliveira AIF, Kusano MS. Crescimento ponderal de prematuros. J. Pediatr. (Rio de J.) 1982; 52 (1/2): $19-20$.

Kramer MS. Intrauterine growth and gestational age determinants. Pediatrics 1987; 80 (4): $502-11$.

Leite ICF. Morbidade e nutrição segundo o peso ao nascer em crianças menores de seis meses atendidas no Instituto Materno Infantil de Pernambuco. Recife, 1990. [Dissertação de Mestrado - Universidade Federal de Pernambuco] 
Lima RT, Marino WT, Lucena L. É ainda o baixo peso ao nascer um problema de saúde pública no Brasil? Rev. IMIP 1998; 12 (1): 3 - 12.

Marchioni DML. Alimentação no primeiro ano de vida: prevalência de consumo de alimentos em dois centros de saúde do Município de São Paulo. São Paulo, 1999. [Dissertação de Mestrado - Faculdade de Saúde Pública da USP]

Marino WT. Estudo descritivo dos recém-nascidos de muito baixo peso em uma maternidade de nível terciário. São Paulo, 2001. [Dissertação de Mestrado Faculdade de Saúde Pública da USP]

Martins CM. A fecundidade paulistana: um estudo de seus diferenciais intraurbanos de desenvolvimento humano e escolaridade. Dissertação de Mestrado. Faculdade de Saúde Pública, Universidade de São Paulo, 1999.

McCORMICK MC. The contribution of low birth weight to infant mortality and childhood morbidity. New England Journal of Medicine 1985; 312:82-90.

Menezes e col. Fatores de risco para a mortalidade perinatal em Pelotas, RS, 1993. Rev. Saúde Públ. 1998; 32: 217 - 24 .

Monteiro CA, Benício MHD’A, Ortiz LP. Tendência secular do peso ao nascer na cidade de São Paulo (1976 - 1998). Rev. Saúde Públ. 2000a; 34 (6 Supl): 26-40. 
Monteiro CA, Szarfarc SC, Mondini L. Tendência secular da anemia na infância na cidade de São Paulo (1984 - 1996). Rev. Saúde Públ. 2000b; 34 (6 Supl): 62-72.

Monteiro CA \& Conde WL. Tendência secular da desnutrição e da obesidade na infância na cidade de São Paulo (1974 - 1996). Rev. Saúde Públ. 2000; 34 (6 Supl): 5261.

Narayanan I. Care of the low birthweight infant in developing countries. Ann. Trop. Paediatr. 1986; 6: $11-15$.

NCHS (NATIONAL CENTER FOR HEALTH STATISTICS). Growth curves for children birth-18 years. United States Department of Health, Education and Welfare. Publication $n^{\circ} 7,1977$.

Neuman NA, Tanaka OY, Szarfarc SC, Guimarães PRV, Victora CG. Prevalência e fatores de risco para anemia no Sul do Brasil. Rev. Saúde Públ. 2000; 34(1): 56-63.

NÓBREGA FJ. Antropometria, patologias e malformações congênitas do recém-nascido brasileiro e estudo de associação com algumas variáveis maternas. Jornal de Pediatria 1995; 59 (2): $110-114$. 
Organização Mundial da Saúde. Grupo Científico de Anemias Nutricionales. Serie de Informes Técnicos 405. Genebra: Organização Mundial da Saúde; 1968.

[OMS] Organización Mundial de la Salud. Lucha contra la anemia mutricional especialmente contra la carencia de hierro. Ginebra; 1975. (OMS - Serie de Informes Técnicos, 580).

[OMS] Organização Mundial da Saúde. Classificação Internacional das Doenças. $10^{\circ}$ revisão II-5: definições, regulamentações, regras, normas para mortalidade $e$ morbidade. São Paulo: Centro Brasileiro de Classificação de Doenças, 1993. [Dados inéditos].

OMS/UNICEF. Reunião conjunta OMS/UNICEF sobre Alimentação de Lactentes e Crianças na Primeira Infância. Genebra, 1979.

Paz SMRS. Prática alimentar e sua relação com o crescimento nos primeiros seis meses de vida. São Paulo, 2000. [Dissertação de Mestrado - Faculdade de Saúde Pública da USP].

PESQUISA NACIONAL SOBRE DEMOGRAFIA E SAÚDE (PNDS) - Relatório Preliminar. BEMFAM (Sociedade Civil de Bem-Estar Familiar no Brasil) Rio de Janeiro, 1997. 
Pojda J, Kelley L. Low birthweight. Geneva; UN ACC Sub-Committee on Nutrition; 2000.

Puffer RR, Serrano CV. Patterns of mortality in childhood. Report of the interAmerican investigation of mortality in childhood. Washington: PAHO, 1973 (PAHO Scientific Publication $\mathrm{n}^{\circ}$ 263).

Santos CD, Santos LMP, Figueiroa JN, Marroquim PMG, Oliveira MAA. Anemia em escolares da primeira série do ensino fundamental da rede pública de Maceió, Alagoas, Brasil. Cad. Saúde Públ. 2002; 18(6): 1757-63.

Silva LSM, Giugliani ERJ, Aerts DRGC. Prevalência e determinantes de anemia em crianças de Porto Alegre, RS, Brasil. Rev. Saúde Públ. 2001; 35(1): 66-73.

Simon VGN. Introdução de alimentos complementares em crianças no primeiro ano de vida nascidas em Hospital Universitário no município de São Paulo. São Paulo, 2001. [Dissertação de Mestrado - Faculdade de saúde Pública da USP].

Smallpeice V \& Davies PA. Immediate feeding of premature infants with undiluted breast milk. Lancet $1964 ; 2: 1349-1352$. 
Souza JB, Gonçalves AL, Mucillo G. Estudo longitudinal da evolução ponderal de crianças pré-termo do nascimento até o sexto mês pós-termo. Rev. Saúde Públ. 1992; $26(5): 350-55$.

Souza SB, Szarfarc SC, Souza JMP. Anemia no primeiro ano de vida em relação ao aleitamento materno. Rev. Saúde Públ. 1997; 31(1): 15-20.

Souza SB; Szarfarc SC; Souza JMP; Veiga GV; Alberico APM; Furumoto RV; Giugliani E; Yuyama; Nagahama D. Prevalência de anemia em crianças menores de um ano em serviços de saúde de cinco cidades brasileiras e sua relação com variáveis demográficas e peso ao nascer [resumo]. Ciênc. Saúde Coletiva 2000; 5 (supl): 81. [Apresentado em Congresso Brasileiro de Saúde Coletiva; 2000 ago - 01 set; Salvador (BA)].

Spinelli MGN. Prática alimentar de crianças menores de um ano de idade, atendidas em unidades básicas de saúde-escola, do Município de Mogi das Cruzes. São Paulo; 2000. [Dissertação de Mestrado - Faculdade de Saúde Pública da USP].

Spinelli MGN. Concentração de hemoglobina, prevalência de anemia e fatores de risco associados, em crianças brasileiras menores de um ano: um estudo multicêntrico de abrangência nacional. São Paulo; 2004. [Tese de Doutorado Faculdade de Saúde Pública da USP]. 
Spolidoro JVN, Müller DP. Alimentação no primeiro ano de vida. Rev. Bras. Nutr. Clín. 2001; 16 (4): 175 - 179.

Szarfarc SC; Cardoso MA; Furumoto RAV; Souza SB. A papa de sal: composição e freqüência de consumo entre crianças atendidas no serviço público de saúde de Santo André, FAISA, em 1993 e 1998. In: Sociedade Brasileira de Alimentação e Nutrição. V Congresso Nacional da Sociedade Brasileira de Alimentação e Nutrição: nutrição, perspectivas para o próximo século; 1999 dez 5-8; São Paulo. São Paulo, SBAN, 1999. p. 110.

Szarfarc SC, Souza SB, Furumoto RAV, Brunken GS, Assis AMO, Gaudenzi EN e col.. Concentração de hemoglobina em crianças do nascimento até um ano de vida. Cad. Saúde Públ. 2004; 20 (1): 266 - 274.

Szarfarc SC. Anemia ferropriva: problema de saúde pública e sua extensão em São Paulo. Bol. Soc. Bras. Hematol. Hemoterap., 10 (149): 98 - 102; jul-set 1988.

Taddei JAAC, Colugnati FAB, Rodrigues EM, Sigulem DM, Lopez FA. Desvios Nutricionais em menores de cinco anos. São Paulo: UNIFESP - Universidade Federal de São Paulo, 2002. 
Torres MAA, Sato K, Queiroz SS. Anemia em crianças menores de dois anos atendidas nas unidades básicas de saúde no Estado de São Paulo, Brasil. Rev. Saúde Públ. 1994; $28(4): 290-4$.

Uchimura TT. Fatores maternos de risco para o baixo peso ao nascer. São Paulo; 2000. [Tese de doutorado - Faculdade de Saúde Pública da USP]

Uchimura TT, Szarfarc SC, Latorre MRDO, Uchimura NS, Souza SB. Anemia e peso ao nascer. Rev. Saúde Públ. 2003; 37(4):397 - 403.

UNICEF. Tendências na amamentação e seu impacto na saúde da criança. Brasil, 1978.

UNICEF, 1981. Breast-feeding and health. Assignment children. Geneva: Unicef.

UNICEF-DEPAS/DIPRO/SISVAM - Secretaria de Saúde do Estado da Bahia. Indicadores do Aleitamento Materno. Uma proposta. Dez 1995.

Venancio SI. Determinantes individuais e contextuais do aleitamento materno exclusivo nos primeiros seis meses de vida em cento e onze municípios do Estado de Sæ̋o Paulo. São Paulo; 2002. [Tese de Doutorado - Faculdade de Saúde Pública da USP] 
Victora CG, Vaughan JP, Lombardi C, Fuchs SMC, Gigante LP, Smith PG, Nobre LC, Teixeira AMB, Moreira LB, Barros FC. Evidence for protection by breast-feeding against infant deaths from infectious diseases in Brazil. Lancet 1987; August 8: 319 22.

Victora CG, Barros FC, Vaughan JP. Epidemiologia da Desigualdade: Um Estudo Longitudinal de 6000 Crianças Brasileiras. São Paulo: Cebes/Hucitec. 1989.

World Health Organization. The incidence of low birth weight. A critical review of available information. World HIth Stat Quart 1980; 33: 197 - 224.

World Health Organization. Contemporary patterns of breast-feeding; Report. Geneva, 1981.

World Health Organization/UNICEF. Proteção, promoção e apoio ao aleitamento materno: o papel especial dos serviços materno-infantis. Genebra: 1989.

[WHO] World Health Organization. Physical status: the use and interpretation of anthropometry: report of a expert Commitee. Geneva; 1995. (Technical Report Series, 854).

World Health Organization. $54^{\text {th }}$ World Health Assembly; Geneva; 2001. 
WORLD HEALTH ORGANIZATION (WHO). Use and interpretation of anthropometric indicators of nutrition status. Bull World Health Organ v. 64, p. 929$41,1986$.

Xavier CC, Abdallah VOS, Silva BR, Mucillo G, Jorge SM, Barbieri MA. Crescimento de recém-nascido pré-termo. J. Pediatr. 1995; 71 (1): 22 - 7.

Xavier CC, Jorge SM, Gonçalves AL. Prevalência do aleitamento materno em recémnascidos de baixo peso. Rev. Saúde Públ. 1991; 25(5): 381-7. 


\section{ANEXO 1}

TERMO DE CONSENTIMENTO PARA PARTICIPAÇÃO NA PESQUISA 
TERMO DE CONSENTIMENTO PARA PARTICIPAÇÃO NA PESQUISA “ALEITAMENTO MATERNO, DIETA DE DESMAME E ANEMIA NO PRIMEIRO ANO DE VIDA, EM CRIANÇAS ATENDIDAS NA REDE PÚBLICA DE SAÚDE"

(de acordo com a resolução 196 de 10/10/1996 do Conselho Nacional de Saúde)

Eu, livremente, permito que meu (minha) filho (a) participe da pesquisa "Aleitamento materno, dieta de desmame e anemia no primeiro ano de vida, em crianças atendidas na rede pública de saúde" sob responsabilidade das pesquisadoras Sonia Buongermino de Souza, Professora Doutora da Faculdade de Saúde Pública da USP e Sophia Cornbluth Szarfarc, Professora Associada da Faculdade de Saúde Pública da USP.

Fui informado(a) sobre o seguinte:

Objetivo da Pesquisa: Verificar a prevalência da anemia no primeiro ano de vida e sua relação com a prática alimentar e com o crescimento e o desenvolvimento, em crianças atendidas em serviços públicos de saúde.

Participação: Responder às perguntas necessárias e permitir que sejam feitas medidas de peso e de altura e a colheita de $20 \mu \mathrm{L}$ de sangue, por puntura do pé, de meu(minha) filho(a), para dosagem de hemoglobina para diagnóstico de anemia. Todos os procedimentos para a colheita de sangue serão feitos com material descartável.

Riscos: Não haverá riscos para a integridade fisica, mental ou moral de meu(minha) filho(a).

Benefícios: As informações obtidas nesta pesquisa poderão ser úteis cientificamente e de ajuda para todos. Se a criança estiver anêmica será encaminhada, imediatamente, ao médico, para tratamento.

Privacidade: Os dados individualizados serão confidenciais. Os resultados coletivos serão divulgados nos meios científicos.

Contato com os pesquisadores: Terei acesso a telefone para esclarecimento de dúvidas ou reclamações. 
ANEXO 2

FORMULÁRIO DE REGISTRO DE DADOS 


\section{ALIMENTAÇÃO NO PRIMEIRO ANO DE VIDA}

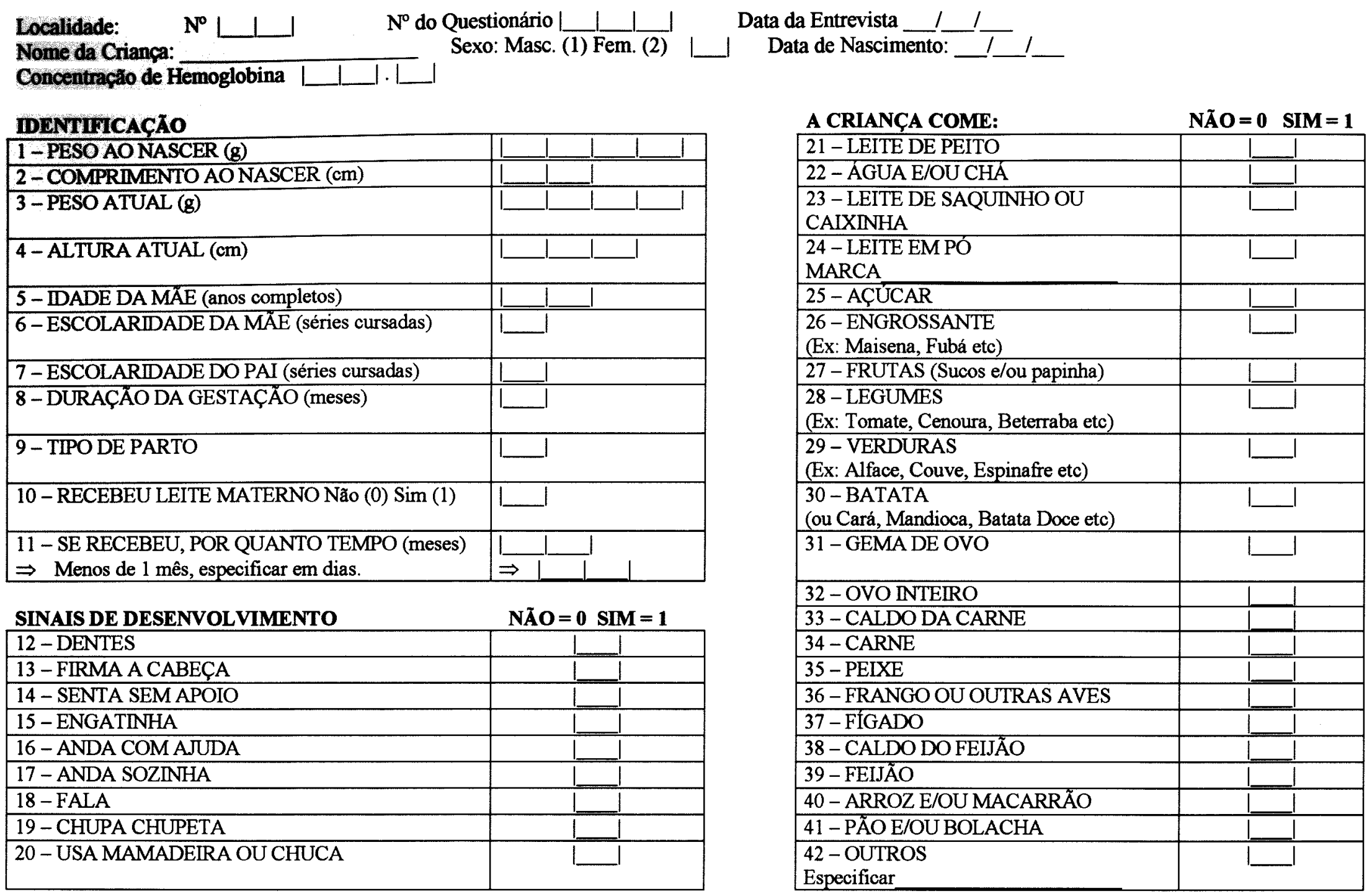

